OPEN ACCESS

Edited by:

Ryan Yuen,

The Hospital for Sick Children,

Canada

Reviewed by:

Steven G. Gray,

St. James's Hospital/Trinity College

Dublin, Ireland

lan Morison,

University of Otago, New Zealand

Jorg Tost,

Commissariat á l'Energie Atomique -

Institut de Genomique, France

${ }^{*}$ Correspondence:

David Monk

dmonk@idibell.cat

Specialty section:

This article was submitted to Epigenomics and Epigenetics,

a section of the journal

Frontiers in Genetics

Received: 13 January 2016

Accepted: 04 April 2016

Published: 26 April 2016

Citation:

López-Abad M, Iglesias-Platas I and Monk D (2016) Epigenetic

Characterization of CDKN1C

in Placenta Samples from

Non-syndromic Intrauterine Growth

Restriction. Front. Genet. 7:62.

doi: 10.3389/fgene.2016.00062

\section{Epigenetic Characterization of CDKN1C in Placenta Samples from Non-syndromic Intrauterine Growth Restriction}

\author{
Miriam López-Abad' ${ }^{1}$, Isabel Iglesias-Platas ${ }^{1}$ and David Monk ${ }^{2 *}$ \\ ${ }^{1}$ Servicio de Neonatología, Sant Joan de Déu, Centro de Medicina Maternofetal y Neonatal Barcelona, Hospital Sant Joan \\ de Déu y Hospital Clínic, Universitat de Barcelona, Barcelona, Spain, ${ }^{2}$ Imprinting and Cancer group, Cancer Epigenetic and \\ Biology Program, Institut d'Investigació Biomedica de Bellvitge, Barcelona, Spain
}

The cyclin-dependent kinase (CDK)-inhibitor 1C (CDKN1C) gene is expressed from the maternal allele and is located within the centromeric imprinted domain at chromosome 11p15. It is a negative regulator of proliferation, with loss-offunction mutations associated with the overgrowth disorder Beckwith-Wiedemann syndrome. Recently, gain-of-function mutations within the PCNA domain have been described in two disorders characterized by growth failure, namely IMAGe (intrauterine growth restriction, metaphyseal dysplasia, adrenal hypoplasia congenita and genital abnormalities) syndrome and Silver-Russell syndrome (SRS). Over-expression of CDKN1C by maternally inherited microduplications also results in SRS, suggesting that in addition to activating mutations this gene may regulate growth by changes in dosage. To determine if CDKN1C is involved in non-syndromic IUGR we compared the expression and DNA methylation levels in a large cohort of placental biopsies from IUGR and uneventful pregnancies. We observe higher levels of expression of CDKN1C in IUGR placentas compared to those of controls. All placenta biopsies heterozygous for the PAPA repeat sequence in exon 2 showed appropriate monoallelic expression and no mutations in the PCNA domain were observed. The expression profile was independent of both genetic or methylation variation in the minimal CDKN1C promoter interval and of methylation of the cis-acting maternally methylated region associated with the neighboring KCNQ1OT1 non-coding RNA. Chromatin immunoprecipitation revealed binding sites for CTCF within the unmethylated CDKN1C gene body CpG island and putative enhancer regions, associated with the canonical enhancer histone signature, H3K4me1 and H3K27ac, located $~ 58$ and 360 kb away. Using 3C-PCR we identify constitutive higher-order chromatin loops that occur between one of these putative enhancer regions and CDKN1C in human placenta tissues, which we propose facilitates expression.

Keywords: imprinting, DNA methylation, placenta, CDKN1C, epigenetics 


\section{INTRODUCTION}

Intrauterine growth restriction (IUGR) is a condition in which a fetus is unable to achieve its genetically determined in utero size and is associated with increased risk of perinatal morbidity and mortality. The mechanisms that lead to IUGR are not completely understood. Etiologically, restricted growth can be of fetal, maternal and placental origin. Aberrant maternal-fetal circulation has been consistently implicated because of the observed abnormalities in Doppler dynamics of the uterine and umbilical arteries, which indicate increased resistance in the maternal spiral arteries and the placental circulation, respectively (Society for Maternal-Fetal Medicine Publications Committee et al., 2012). Pregnancies that are complicated by IUGR often require early elective delivery due to higher risk of fetal distress, resulting in additional complications associated with prematurity (Miller et al., 2009) which require prolonged admission in neonatal intensive care.

Chromosomal abnormalities are often a cause of severe growth restriction (Romero et al., 2015). With the advent of genome-wide technologies, altered gene expression profiles in the fetus or placenta are commonly being described in IUGR and other pregnancy complications. These abnormal expression profiles are often associated with increased epigenetic variance, suggesting links between underlying chromatin dynamics and fetal growth. In particular, imprinted genes, of which there are $\sim 150$ described in the human genome, have been shown to be essential for appropriate fetal and placenta development. Emerging evidence implicates aberrant expression levels of imprinted genes in not only classical imprinting disorders (reviewed in Eggermann et al., 2015), but also in many common multifactorial human diseases, which include complications of pregnancy such as IUGR, pre-eclampsia (reviewed in Monk, 2015) and postnatal disorders including obesity and type 2 diabetes (Kong et al., 2009).

\section{Genomic Imprinting}

Imprinted genes encode products implicated in diverse physiological processes, many of them playing a role in growth and development. The molecular mechanisms regulating genomic imprinting involve the establishment of parent-specific epigenetic modifications in the germline, which result in monoallelic expression of transcripts in a parent-of-origin dependent manner (Ferguson-Smith, 2011). Until recently, it was thought that imprinted genes have a tendency to cluster together as a result of sharing cis-regulatory elements, including differentially methylated regions (DMRs) that inherit methylation from one of the two gametes. However, recent genome-wide screens for novel imprinted loci have identified placenta-specific maternally methylated DMRs that are more prevalent in the human genome than ubiquitous imprinted domains (Court et al., 2014b), and that do not orchestrate imprinting of neighboring genes (Sanchez-Delgado et al., 2015).

\section{The KCNQ1OT1 Imprinted Domain}

Distal mouse chromosome 7 harbors the largest known imprinted cluster and is highly conserved in humans. Two germline DMRs control different sets of imprinted transcripts within this $>1 \mathrm{Mb}$ cluster, divided into two functionally independent domains. The centromeric domain is controlled by the paternally methylated H19/IGF2:IG-DMR (note adoption of recommended DMR name as recommended by the European Network for Human Congenital Imprinting Disorders EUCID.net ${ }^{1}$. Also known as the H19 ICR or ICR1; Thorvaldsen et al., 1998), whereas the telomeric domain is regulated by the KCNQ1OT1:TSS-DMR (also known as KvDMR1 or ICR2; Lee et al., 1997; Caspary et al., 1998). This second DMR is a CpG island within intron 10 of the Kcnq1/KCNQ1 gene that inherits methylation from oocytes (Hiura et al., 2006) and is the promoter for the long ncRNA KCNQ1OT1 (also known as LIT1). In the mouse, this long ncRNA recruits the histone methyltransferases G9a and EZH2 to the promoters of the flanking genes depositing trimethylation of lysine 27 of histone $\mathrm{H} 3$ (H3K27me3) and H3K9me2 (Lewis et al., 2004; Umlauf et al., 2004; Mohammad et al., 2012) on the paternal allele bring about imprinting in the placenta (Okae et al., 2012). Truncation of Kcnq1ot1 results in loss of imprinted expression of all genes in the placenta, confirming that the products of transcription are essential for imprinting maintenance (Mancini-Dinardo et al., 2006). Interestingly, despite conserved expression of KCNQ1OT1, imprinting of the placenta-specific transcripts within the human orthologous domain is not conserved, since their promoters are not decorated with allelic repressive histone modifications (Monk et al., 2006) (Figure 1A). However three genes, CDKN1C, PHLDA2, and SLC22A 18 are imprinted, being monoallelically expressed in both placenta and fetal tissues (Yatsuki et al., 2002; Monk et al., 2006).

\section{The CDKN1C Gene}

Cyclin-dependent kinase (CDK) Inhibitor 1C (also known as p57Kip2) has four exons and was first discovered as a result of sequence similarity with other CDK inhibitors in a twohybrid screening (Hatada and Mukai, 1995; Matsuoka et al., 1995). CDKN1C mRNA transcripts are found in placenta, heart, brain, lung, skeletal muscle, kidney, pancreas, and testis by northern analysis (Matsuoka et al., 1995). Microarray expression analysis reveals that $C D K N 1 C$ is most abundant in placenta compared to somatic tissues (Sood et al., 2006). The protein has highly conserved N-terminal CDK inhibition and C-terminal domains. The human protein, but not the mouse, also contains a proliferating cell nuclear antigen (PCNA) binding domain required for preventing DNA replication (Watanabe et al., 1998). In addition CDKN1C has a QT-box involved in protein-protein interactions and a unique proline-rich and acidic domain in the mouse, replaced with proline-alanine (PAPA) repeats in humans, which are involved in mitogen-activated protein kinase (MAPK) phosphorylation (Lee et al., 1995). The absence of conserved sequence in the mid-region of the protein could be attributable to the lack of function, merely acting as a spacer region to separate the functional N- and C-terminal domains (Matsuoka et al., 1995; Tokino et al., 1996) (Figure 1B).

\footnotetext{
${ }^{1}$ http://www.imprinting-disorders.eu
} 


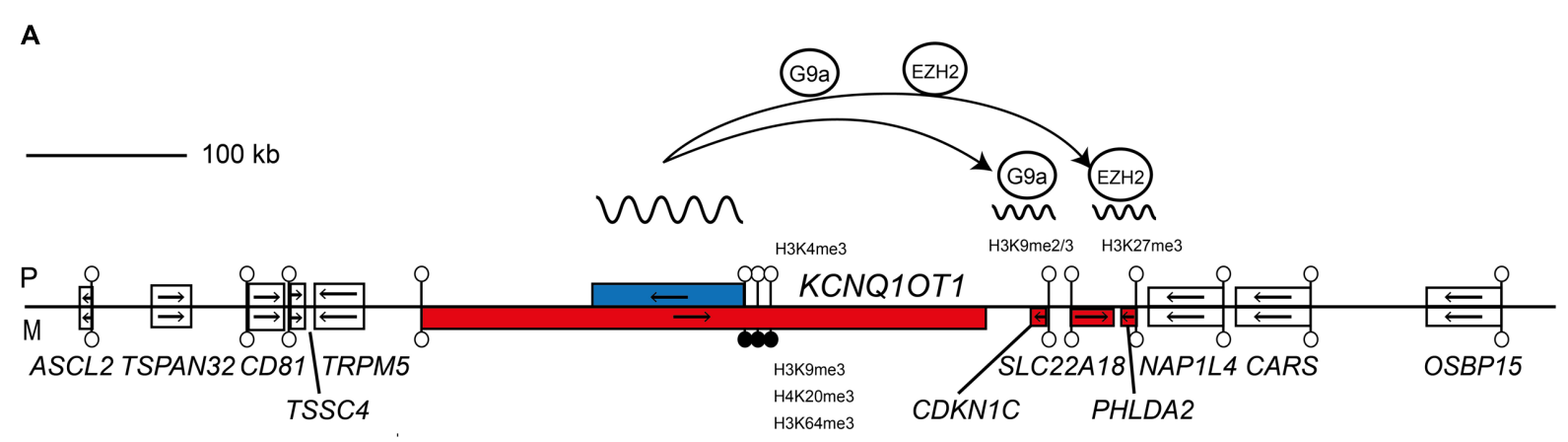

B

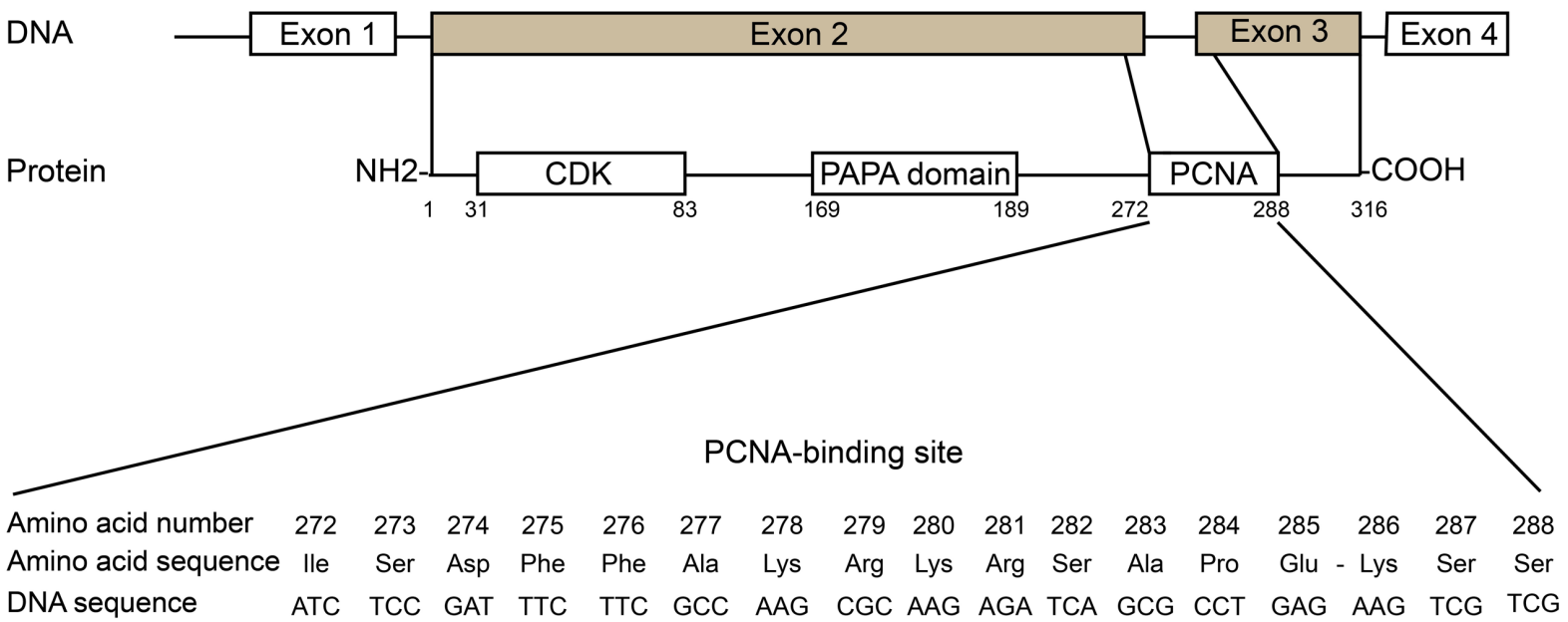

FIGURE 1 | Schematic representation shows the relative organization of genes, CpG islands and differentially methylated regions (DMRs) for KCNQ10T1-CDKN1C domain. (A) The centromeric imprinting domain on human chromosome 11p15.5 highlighting the role of the ncRNA KCNQ1OT1 in recruiting the G9a and EZH2 histone methyltransferase complexes to the paternal allele of CDKN1C. Open boxes depict non-imprinted genes. Blue boxes are paternally expressed genes; red boxes are maternally expressed genes, respectively. Lollipops signify CpG islands with open circles unmethylated and black circles methylated. The arrows show the direction of transcription. (B) Structural features and functional domains of the CDKN1C gene and protein. The CDKN1C possesses four exons with exons 2 and 3 encoding the functional protein. The protein has three key domains: a conserved amino-terminal containing the CDK inhibitory domains; the proline-alanine repeat (PAPA) domain; and the proliferating cell nuclear antigen (PCNA) domain which contains a nuclear localization signal. The nucleotide and amino acid sequence of the PCNA domain is shown.

\section{CDKN1C Cell Cycle Function}

CDKN1C is one of the CDKs inhibitors belonging to the Cip/Kip family, which includes CDKN1A (p21cip1) and CDKN1B (p27kip1). These proteins are required for cell cycle transition and play important roles in coordinating cell proliferation, differentiation and maintenance of the non-proliferative state of cells. Cdknlc is primarily expressed in cells that are exiting cell cycle but are not terminally differentiated and shows specificity for G1 CDKs. It can bind several CDKs in a cyclindependent manner, including cyclin $\mathrm{A} / \mathrm{Cdk} 2$, cyclin $\mathrm{E} / \mathrm{Cdk} 2$, cyclin $\mathrm{E} / \mathrm{Cdk} 3$, cyclin $\mathrm{D} 2 / \mathrm{Cdk} 4$ and, to a lesser extent, cyclin D2/Cdk6. Furthermore, CDKN1C can inhibit the kinase activity of the G1 cyclin Cdk2, Cdk3, and Cdk4 complexes. Therefore CDKN1C is capable of inhibiting several CDK with demonstrated roles in the G1/S-phase transition. However, in mouse embryonic fibroblasts and placenta from null animals, disruption of the protein does not affect the activities of Cdk2 and Cdk4 (Takahashi et al., 2000), suggesting that Cdkn1c may have a biological activity other than inhibition of Cdk activities, presumably linked with PCNA-associated DNA replication regulation (Watanabe et al., 1998), thus affecting cell cycle regulation via different mechanisms.

\section{Mutations of Human CDKN1C and Growth}

In addition to large copy-number alterations of $11 \mathrm{p} 15$ that lead to developmental phenotypes (Begemann et al., 2012; Cerrato et al., 2014), mutations of CDKN1C also give rise to growth abnormalities. Since CDKN1C functions as a negative regulator of cellular proliferation, aberrations in this gene are predicted to result in over-proliferation and predisposition to cancer. Indeed, maternally inherited loss-of-function mutations are associated with $5 \%$ of sporadic and $50 \%$ of familial cases of Beckwith-Wiedemann syndrome (BWS; Lim and Maher, 2010; Eggermann et al., 2014). These genetic alterations in BWS are 
rare compared to epimutations of the KCNQ1OT1:TSS-DMR that results in overexpression of the KCNQ1OT1 ncRNA and concomitant repression of both alleles of CDKN1C (Diaz-Meyer et al., 2003).

Recent reports of maternally inherited gain-of-function point mutations within the PCNA-binding domain are associated with the growth restriction disorders IMAGe (Arboleda et al., 2012) and Silver-Russell syndromes (SRS; Brioude et al., 2013). This domain is required for PCNA-dependent and CRL4Cdt2mediated ubiquitination of three lysine residues, Lys278, Lys280, and Lys286 (Kirchmaier, 2011), with mutations presumably increasing the stability of the protein (Hamajima et al., 2013). Interestingly, expression of IMAGe-associated CDKN1C mutations does not interfere with the ability of CDKN1C to inhibit the cell cycle in phase G0/G1 through binding of the CDK, suggesting that domain-specific mutations have differential effects on cell-cycle progression and developmental processes (Arboleda et al., 2012).

\section{CDKN1C and Placenta Development}

During mid-to-late mouse placental development $C d k n 1 c$ is expressed in giant trophoblast cells, glycogen cells within the junctional zone and the syncytiotrophoblast (Westbury et al., 2001; Tunster et al., 2011). Mice that express Cdkn1c at twofold the normal endogenous level are growth restricted from embryonic day E13.5, whereas mice deficient for Cdkn1c were heavier at the same time point (Andrews et al., 2007). Studying growth dynamics reveals that $C d k n 1 c$ mutant embryos are $\sim 15 \%$ heavier than wild-type embryos at E15.5, $8 \%$ heavier at E18.5, with the difference diminishing until it is no longer apparent at birth (Tunster et al., 2011). Placentae of Cdkn1c homozygotes and heterozygous mice inheriting a targeted deletion from their mothers are larger than those of wildtype mice. This enlargement was associated with prominent proliferation of the labyrinthine and spongiotrophoblasts layers, disordered vascularization and glycogen storage (Takahashi et al., 2000) with substantial thrombotic lesions (Tunster et al., 2011). The severe placental abnormalities observed in Cdkn1c mutant mice preceded the attenuated overgrowth described previously. This loss of growth potential late in gestation is a classic indicator of placental insufficiency. Furthermore, the overgrowth of mutant mice decreased in the face of increasing intrauterine competition, suggesting that $C d k n 1 c$ is involved in the allocation of the maternal resources via the placenta (Tunster et al., 2011).

It is currently unknown if such dosage effects are observed in humans, since the human placenta has a hemochorial structure lacking a cell type equivalent to the giant trophoblast cell in mice (Carter and Enders, 2004). Therefore the role of CDKN1C in the human placenta might differ from that in the mouse. Several small studies have investigated changes in CDKN1C expression in human placenta cohorts with heterogeneous clinical characteristics (healthy pregnancies, preeclampsia, small for gestational age, and IUGR), with consistent up-regulation observed in IUGR suggesting that deregulation of this genes might play a role in prenatal growth (McMinn et al., 2006; Cordeiro et al., 2014). To further clarify the role of CDKN1C in fetal growth we have performed placental expression and DNA methylation profiling in normal and non-syndromic IUGR placental tissues. Combined interrogation of publicly available CTCF ChIP-seq and ChIA-PET data with molecular confirmation in placenta shows that CDKN1C physically interacts with putative long-range enhancer regions that we propose form constitutive chromatin loops and regulate expression.

\section{MATERIALS AND METHODS}

\section{The Placenta Cohort}

Seventy-seven pregnant women delivering their babies in Sant Joan de Déu Hospital, Barcelona, participated in the study, contributing 89 newborns. The protocol was approved by both the Sant Joan de Déu Hospital and IDIBELL Research and Ethics Committees (PI35/07 and PR006/08) and individual informed consent was obtained. Upon delivery, the placentae were weighed and biopsies from the fetal side adjacent to the umbilical cord insertion site were excised. The tissue was thoroughly rinsed in saline and snap frozen in liquid nitrogen. Maternal blood samples were collected in EDTA tubes and frozen at $-20^{\circ} \mathrm{C}$ until processed. Clinical information on pregnancy course for the anonymized samples was recorded. For the purpose of the analysis, subgroups were established according to the characteristics of the pregnancy and of the newborn (term or preterm, IUGR or non-IUGR, conceived spontaneously or by assisted reproduction). According to length of gestation, newborns were classified in: term ( $\geq 37$ weeks), late and moderate preterm $(>32$ and $<37$ weeks) and very preterm ( $\leq 32$ weeks). IUGR was defined as a weight below the third percentile for gestational age or below the 10th percentile when accompanied by fetal Doppler flow abnormalities (Tables 1-3).

\section{Other Tissues and Cell Lines}

Control lymphoblastoid cell lines were established by EBV transformation of peripheral blood cells and propagated in RPMI media supplemented with 10\% fetal calf serum (FCS) and antibiotics. The human TCL1 placental trophoblast cell line was grown in Dulbecco's modified Eagle's medium supplemented with 10\% FCS and antibiotics. Prior to ChIP and 3C, the cell line $11 \mathrm{p} 15$ methylation signatures were compared to normal leukocytes and placenta samples to ensure that the transformation process had not altered the epigenetic profile.

\section{Nucleic Acid Extraction}

Genomic DNA from placenta samples was prepared by SDS/Proteinase K lysis followed by phenol/chloroform extraction and ethanol precipitation. DNA from blood and cell lines was extracted using a commercial kit (QIAamp DNA Blood Midi $\mathrm{Kit}^{\circledR}$, QIAGEN), following the manufacturer's instructions. Total RNA was extracted using Trizol ${ }^{\circledR}$ (Invitrogen), and $1 \mu \mathrm{g}$ of RNA was treated with DNase (amplification grade DNase I, Invitrogen) prior to RT. Reverse transcription was performed with MMLV 
retrotranscriptase (Promega) and random primers (Promega) following the manufacturer's instructions.

\section{Genotyping PCR Reactions}

Sequences were obtained for all DNA samples using PCR and direct sequencing of the resulting amplicons using primers for the PCNA domain of CDKN1C, the minimal promoter of CDKN1C and the putative enhancer regions (see Supplementary Table S1 for primer sequences). Approximately $200 \mathrm{ng}$ genomic DNA was amplified using BioTaq DNA Polymerase (Bioline). PCR was performed for 35 cycles of denaturation at $94^{\circ} \mathrm{C}$ for $30 \mathrm{~s}$, followed by $30 \mathrm{~s}$ annealing and extension at $72^{\circ} \mathrm{C}$ for $60 \mathrm{~s}$. PCR amplicons were purified using ethanol precipitation and

TABLE 1 | Clinical characteristics of the newborns in the sample.

\begin{tabular}{|c|c|c|c|}
\hline \multirow{2}{*}{$\begin{array}{l}\text { Newborn } \\
\text { characteristics }\end{array}$} & \multicolumn{2}{|c|}{$n(\%)$} & \multirow[t]{2}{*}{$p$-value } \\
\hline & IUGR $(n=36)$ & Control $(n=53)$ & \\
\hline Gender: boys & $14(38.9)$ & $28(52.8)$ & 0.196 \\
\hline \multicolumn{4}{|l|}{$\begin{array}{l}\text { Gestational age group } \\
\text { (w = weeks) }\end{array}$} \\
\hline Term $(\geq 37 w)$ & $13(36.1)$ & $21(39.6)$ & \\
\hline $\begin{array}{l}\text { Late preterm } \\
(34+1-36+6 w)\end{array}$ & $11(30.6)$ & 7 (13.2) & 0.226 \\
\hline $\begin{array}{l}\text { Moderate premature } \\
(32+1-34 \mathrm{w})\end{array}$ & $6(16.7)$ & $11(20.8)$ & \\
\hline Very premature ( $\leq 32 \mathrm{w}$ ) & $6(16.7)$ & $14(26.4)$ & \\
\hline Multiple gestation & $11(30.6)$ & $19(35.8)$ & 0.604 \\
\hline No previous gestation & $21(58.3)$ & $36(67.9)$ & 0.355 \\
\hline Conception by ART & $11(30.6)$ & $17(32.1)$ & 0.880 \\
\hline Preeclampsia & $8(22.2)$ & $2(3.8)$ & $0.014^{*}$ \\
\hline Labor & $18(50.0)$ & $32(60.4)$ & 0.333 \\
\hline \multirow{2}{*}{$\begin{array}{l}\text { Delivery by cesarean } \\
\text { section }\end{array}$} & $23(63.9)$ & $30(56.6)$ & 0.492 \\
\hline & \multicolumn{2}{|c|}{ Mean \pm SD } & \\
\hline Gestational age (w) & $35.1 \pm 3.5$ & $33.8 \pm 7.3$ & 0.274 \\
\hline \multicolumn{4}{|l|}{$\begin{array}{l}\text { Anthropometric data at } \\
\text { birth }\end{array}$} \\
\hline Birth weight (g) & $1841 \pm 564$ & $2340 \pm 952$ & $<0.003^{*}$ \\
\hline Birth weight SDS & $-1.55 \pm 0.68$ & $0.22 \pm 0.72$ & $<0.0001^{*}$ \\
\hline Length (cm) & $43.0 \pm 4.3$ & $45.0 \pm 6.2$ & 0.123 \\
\hline Length SDS & $-1.26 \pm 1.07$ & $0.21 \pm 0.68$ & $<0.0001^{*}$ \\
\hline $\begin{array}{l}\text { Head circumference } \\
(\mathrm{HC}, \mathrm{cm})\end{array}$ & $30.4 \pm 2.6$ & $31.5 \pm 4.3$ & 0.190 \\
\hline HC SDS & $-1.22 \pm 0.82$ & $0.20 \pm 0.76$ & $<0.0001^{*}$ \\
\hline Placental weight (g) & $396 \pm 133$ & $578 \pm 203$ & $<0.0001^{*}$ \\
\hline $\begin{array}{l}\text { Birth weight to placenta } \\
\text { ratio }\end{array}$ & $4.89 \pm 1.20$ & $4.25 \pm 1.29$ & $0.034^{*}$ \\
\hline
\end{tabular}

Standard deviation score (SDS), a variable that represent the distance of a data point to the mean of the distribution as measured in SDs. Values are expressed as number (n) and percentage and were compared between groups by Chi-square tests. Continuous variables are summarized as mean \pm standard deviation and Student's t-testing was used for statistical comparison. ${ }^{*} P<0.05$ were considered significant. Note, since there are methylation differences in the placenta that are due to gestational age both IUGR and control patients were recruited amongst term and preterm deliveries to minimize the difference between groups regarding this parameter.
TABLE 2 | Maternal data.

\begin{tabular}{|c|c|}
\hline Maternal characteristics & $n(\%)$ \\
\hline Ethnicity: Caucasian & $55(71.4)$ \\
\hline Parity: primiparous & $49(63.6)$ \\
\hline Assisted reproduction & $19(24.7)$ \\
\hline \multicolumn{2}{|l|}{ Previous obstetric history } \\
\hline None & $53(68.8)$ \\
\hline Infertility & $12(15.6)$ \\
\hline Gestational hypertension/Pre-eclampsia & $3(3.9)$ \\
\hline Recurrent miscarriage $(\geq 3)$ & $3(3.9)$ \\
\hline Previous IUGR & $1(1.3)$ \\
\hline Other & $2(2.6)$ \\
\hline Missing & $3(3.9)$ \\
\hline Multiple gestation & $19(24.7)$ \\
\hline Cesarean section & $41(53)$ \\
\hline Pre-eclampsia & $9(11.7)$ \\
\hline \multicolumn{2}{|l|}{ Pre-existing conditions } \\
\hline None & $58(75.3)$ \\
\hline Chronic hypertension & $5(6.5)$ \\
\hline Psychologic/psychiatric disorders & $2(2.6)$ \\
\hline \multicolumn{2}{|l|}{ Gestational age group } \\
\hline Term $(\geq 37 w)$ & $34(44.2)$ \\
\hline Late preterm $(34+1-36+6$ w) & $13(16.9)$ \\
\hline Moderate preterm (32 - 34 w) & $14(18.2)$ \\
\hline \multirow[t]{2}{*}{ Very preterm ( $\leq 32 \mathrm{w})$} & $16(20.8)$ \\
\hline & Mean \pm SD \\
\hline Age at delivery (years) & $32.5 \pm 6.0$ \\
\hline Height (cm) & $162.6 \pm 7.1$ \\
\hline \multicolumn{2}{|l|}{ Weight (kg) } \\
\hline Pre-pregnancy & $64.9 \pm 15.4$ \\
\hline At delivery & $76.7 \pm 14.8$ \\
\hline Gestational age at delivery (weeks) & $35.0 \pm 4.7$ \\
\hline
\end{tabular}

Quantitative values are expressed as number ( $n$ ) and percentage. Continuous variables are summarized as mean \pm standard deviation.

subsequently sequenced with the BigDye Terminator reaction kits on an ABI 3730 DNA analyser (PE Biosystems).

\section{Quantitative Polymerase Chain Reaction}

Expression of CDKN1C was analyzed by quantitative realtime RT-PCR with a fluorochrome $\left(\mathrm{SYBR}^{\circledR}\right.$ Green) assay and normalized against RPL19 (Iglesias-Platas et al., 2014). This housekeeping gene was selected because of optimal expression stability in placental tissue compared to other commonly used housekeeping genes (Supplementary Table S2). Primers were designed in different exons or across intron/exon boundaries to avoid amplifying contaminating genomic DNA (see Supplementary Table S1 for primer sequences). The assays were run in triplicate in 384 well plates in a 7900HT Fast Real Time PCR System (Applied Biosystems). Dissociation curves were obtained at the end of each reaction to rule out the presence of primer dimers or unexpected DNA species in the reaction. Non-template controls, an interplate control and standard curves from the same serial dilutions of cDNA obtained from pooled normal placental tissue were included in each assay. Results were analyzed with the SDS 2.3 software (Applied Biosystems). The 
TABLE 3 | Maternal data by study group.

\begin{tabular}{|c|c|c|c|}
\hline \multirow{2}{*}{$\begin{array}{l}\text { Maternal } \\
\text { characteristics }\end{array}$} & \multicolumn{2}{|c|}{$n(\%)$} & \multirow[t]{2}{*}{$p$-value } \\
\hline & IUGR ( $n=34)$ & Control $(n=43)$ & \\
\hline Ethnicity: Caucasian & $27(79.4)$ & $28(65.1)$ & 0.489 \\
\hline Parity: primiparous & $20(58.8)$ & $29(67.4)$ & 0.435 \\
\hline Assisted reproduction & $9(26.5)$ & $10(23.3)$ & 0.794 \\
\hline $\begin{array}{l}\text { Previous obstetric } \\
\text { history }\end{array}$ & $11(33.3)$ & $10(24.4)$ & 0.396 \\
\hline Singleton gestation & $9(26.5)$ & $10(23.3)$ & 0.745 \\
\hline Cesarean section & $21(61.8)$ & $20(46.5)$ & 0.183 \\
\hline Labor & $18(52.9)$ & $31(27.9)$ & 0.083 \\
\hline Pre-eclampsia & $8(23.5)$ & $1(2.3)$ & $0.009^{*}$ \\
\hline $\begin{array}{l}\text { Healthy before } \\
\text { pregnancy }\end{array}$ & $22(68.8)$ & $36(87.8)$ & $0.046^{*}$ \\
\hline Chronic hypertension & $4(12.5)$ & $1(2.4)$ & 0.161 \\
\hline \multicolumn{4}{|l|}{ Gestational age group } \\
\hline Term ( $\geq 37 w)$ & $13(38.2)$ & $21(48.8)$ & \\
\hline $\begin{array}{l}\text { Late preterm } \\
(34+1-36+6 w)\end{array}$ & $11(32.4)$ & $2(4.7)$ & \\
\hline $\begin{array}{l}\text { Moderate preterm } \\
(32-34 \mathrm{w})\end{array}$ & $5(14.7)$ & $9(20.9)$ & \\
\hline Very preterm ( $\leq 32 \mathrm{w})$ & $5(14.7)$ & $11(25.6)$ & \\
\hline Age at delivery (years) & $33.2 \pm 6.3$ & $32.0 \pm 5.8$ & 0.428 \\
\hline Height (cm) & $162.1 \pm 7.0$ & $163.0 \pm 7.3$ & 0.621 \\
\hline \multicolumn{4}{|l|}{ Weight (kg) } \\
\hline Pre-pregnancy & $63.0 \pm 15.7$ & $66.3 \pm 15.2$ & 0.390 \\
\hline At delivery & $73.9 \pm 15.2$ & $79.0 \pm 14.3$ & 0.181 \\
\hline $\begin{array}{l}\text { Gestational age at } \\
\text { delivery (weeks) }\end{array}$ & $35.5 \pm 3.6$ & $34.6 \pm 5.5$ & 0.401 \\
\hline
\end{tabular}

Mothers were classified in the UGR group if any of the babies in the current gestation fulfilled diagnostic criteria for IUGR. Quantitative values are expressed as number (n) and percentage and were compared between groups by Chi-square tests. Continuous variables are summarized as mean \pm standard deviation and Student's t-testing was used for statistical comparison. ${ }^{*} P<0.05$ were considered significant.

DataAssist v2.0 ${ }^{\circledR}$ software (Applied Biosystems) was used for exclusion of outlier replicates and for interplate standardization for comparisons. Only samples with two or more valid readings per triplicate were included. Analysis of the results was performed using the comparative $\Delta \Delta \mathrm{CT}$ (RQ) method (Schmitthen and Livak, 2008).

\section{Assessment of Imprinted Expression}

Analysis of allelic expression was determined using PCR across the polymorphic PAPA repeat in the second exon of CDKN1C (see Supplementary Table $\mathbf{S 1}$ for primer sequences). The PCRs were performed with Immolase Taq polymerase (Bioline) for 40 cycles with an annealing temperature of $60^{\circ} \mathrm{C}$. The resulting PCR products were separated on a $4 \%$ agarose gel stained with SYBR safe (Thermo Fisher Scientific). All placental DNA samples were genotyped to identify heterozygous individuals. Expression was then analyzed in heterozygous samples by RT-PCR with imprinting confirmed if a single band was observed in the RTPCR product of a heterozygous sample. In these samples, the parental origin of expression was determined, when possible, by assessing the maternal genotype. In addition, RT-PCR was performed on RT-positive and negative samples in order to rule out genomic contamination.

\section{Allele-Specific Bisulfite PCR}

Approximately $1 \mu \mathrm{g}$ DNA was subjected to sodium bisulfite treatment and purified using the EZ GOLD methylation kit (ZYMO, Orange, CA, USA) and $\sim 50 \mathrm{ng}$ of converted DNA used for all bisulfite PCR reactions. Bisulfite PCR primers for each region were used with Immolase Taq polymerase (Bioline, London, UK) at 45 cycles with an annealing temperature of $53^{\circ} \mathrm{C}$ (see Supplementary Table S1 for primer sequences). The resulting PCR product was cloned into pGEM-T easy vector (Promega), transfected into JM109 bacteria and individual colonies sequencing using standard T7 sequence primer.

\section{Methylation Analysis by Bisulfite Pyrosequencing}

Bisulfite treatment of $1 \mu \mathrm{g}$ of DNA was performed with the EZ Gold in a 96-well plate format (EZ-96 DNA MethylationGoldTM $^{\circledR}$ Kit, Zymo Research), following the manufacturer's protocol. A commercial control was used as reference for bisulfite-converted fully methylated DNA (EpiTect Control $\mathrm{DNA}^{\circledR}$, methylated, Qiagen). Pyrosequencing was selected for the quantitative assessment of DNA methylation at the KCNQ1OT1:TSS-DMR, the CDKN1C promoter and enhancer regions using standard primers with the exception that the reverse primer was biotin-labeled. Immobilization of the PCR products for purification was achieved by streptavidin-coated sepharose beads (Qiagen) with the use of the PyroMark Q96 Vacuum Prep Workstation ${ }^{\circledR}$ and sequenced using a PyroMark Q96 MD machine according to the manufacturer's instructions.

\section{Western Blot Analysis}

Proteins from placenta samples with opposing CDKN1C transcript abundance as determined by qRT-PCR were extracted in standard lysis buffer $(50 \mathrm{mM}$ Tris $7.5 \mathrm{pH}, 150 \mathrm{mM} \mathrm{NaCl}$, $1 \mathrm{mM}$ EDTA) containing $1 \%$ SDS with sonication to disrupt genomic DNA. Twenty-five micrograms $\beta$-mercaptoethanol denatured lysates were separated by PAGE gel electrophoresis and blotted onto a nitrocellulose transfer membrane (Whatman, Life Sciences). The membrane was blocked in 5\% milk PBS-T and immunoprobed with antibodies raised against CDKN1C (Abcam anti-p57kip2: ab75974) and $\beta$-actin (Sigma: A1978). Washed membranes were incubated with corresponding peroxidaseconjugated secondary antibody. The immunoreactive proteins were visualized using the Immobilon chemiluminescent HRP substrate detection kit (Millipore). Bands were quantitated by direct scanning of the western blot films and processed with ImageJ software.

\section{Chromatin Immunoprecipitation}

One hundred micrograms of snap frozen placental tissue were reduced to powder with a pestle and mortar under liquid nitrogen. The pulverized placenta sample was cross-linked with $1 \%$ formaldehyde for $7 \mathrm{~min}$ at room temperature and the reaction blocked by adding glycine to a final concentration of 0.125 M. Similar cross-linking protocols were used for $\sim 80$ 
million lymphoblastoid cells. Approximately $100 \mu \mathrm{g}$ chromatin were used for each immunoprecipitation reaction with Protein $G$ magnetic beads (Millipore, 16-157) and an antibody raised against CTCF (Millipore, 07-729). For each ChIP, a fraction of the input chromatin (5\%) was also processed for DNA purification and a mock immunoprecipitation with a neutral, unrelated IgG (Millipore PP64B Lot: 1968270) antiserum was carried out in parallel. The levels of immunoprecipitated chromatin at specific regions were determined by standard PCR (see Supplementary Table S1 for primer sequences).

\section{C Analysis}

The chromatin conformation capture (3C) protocol was performed as previously described (Court et al., 2014a; IglesiasPlatas et al., 2014). Briefly, HindIII was used to digest $1 \times 10^{7}$ formaldehyde cross-linked nuclei from the placental cell line TCL1 (overnight digestion, 1200 U, NEB). Following efficiency restricted enzyme digestion the chromatin was ligated overnight in a $500 \mu \mathrm{l}$ reaction volume using 1950 units of T4 ligase (Fermentas). DNA was decross-linked by incubating overnight at $65^{\circ} \mathrm{C}$ and purified using phenol/chloroform extraction. This DNA was used for PCR to determine long-range chromatin interactions, using constant primers in the unmethylated CDKN1C gene body CpG island (see Supplementary Table S1 for primer sequences). Primer efficiency was determined using digested and ligated BAC DNA. All 3C experiments were performed in two technical replicates.

\section{Statistical Analysis}

Clinical and molecular data were introduced in a Statistical Package for Social Sciences (SPSS ${ }^{\circledR}$, IBM) software v17.0 database. Expression levels were expressed in logarithmic scale in order to achieve a variable distribution closer to normality and subsequently analyzed against clinical values. Continuous variable are summarized throughout the manuscript as mean \pm standard deviation (SD) and qualitative variables as number and percentage. Comparisons between groups were evaluated with chi-square for categorical variables and $t$-Student test (for two groups, 2-tailed analysis) or ANOVA (more than two groups) for continuous variables. Non-parametric tests were applied where indicated. Relationships between variables were explored by Pearson's correlation and subsequently introduced in multiple regression models to adjust for possible interactions or confounding factors. Results were considered significant if the $p$-value was under 0.05 . This study was sufficiently powered to detect differences in expression of 0.7 SDs between groups (statistical power 80\%) and correlations with a Pearson's r coefficient greater than 0.3 between gene expression and clinical variables (statistical power $86 \%$ ).

\section{RESULTS}

\section{Cohort Description}

Eighty-nine placental samples were obtained from 77 pregnancies. The samples corresponded to 15 twin pregnancies (both newborns analyzed in eight sets and only one in the other seven) and two triplet pregnancies contributing six newborns to the study.

Most mothers (71.4\%) were of Caucasian origin and were healthy before pregnancy. Characteristics of the case and the control groups are summarized in Tables 1-3. Due to the high-risk obstetric characteristics of our population (IUGR, prematurity, complications of pregnancy), there was a high rate of cesarean section (53\%).

Thirty-six of the fetuses were diagnosed with IUGR during pregnancy. Mothers of IUGR babies had a higher prevalence of preeclampsia $(23.5 \%$ vs. $2.3 \%$, Chi-square $p=0.01)$ or chronic hypertension. There were no differences regarding primiparity (58.3\% vs. $67.9 \%$, Chi-square $p=0.35)$, delivery by cesarean section ( $63.9 \%$ vs. $56.6 \%$, Chi-square $p=0.49)$ or in the percentage of mothers undergoing labor $(50.0 \%$ vs. $60.4 \%$, Chi-square $p=0.33$ ) between IUGR and normally grown gestations. Conception by ART was equally frequent in both groups $(30.6 \%$ vs. $32.1 \%$, Chi square $p=0.88)$. IUGR and normally grown fetuses were comparable in their remaining clinical characteristics except, by definition, size for gestational age at birth (Student's $t p<0.001$ ) and the incidence of detection of Doppler flow abnormalities (Chi-square $p<0.001$ ).

\section{Increased Levels of CDKN1C in IUGR Placentae}

Expression levels of CDKN1C relative to the endogenous RPL19 gene were 1.4 times higher in the IUGR group in a univariate analysis (IUGR RQ $0.77 \pm 0.09$ vs. controls $0.56 \pm 0.06$, Students' $t p=0.04$ ) (Figure 2A). For a better fitting in statistical analysis, RQ was transformed by $\log 10$, rendering a distribution closer to normality. We found no correlation between CDKN1C and maternal age, height or weight or with gestational age or anthropometric parameters of the baby, suggesting that the relationship between expression and growth is specific to an effect of IUGR rather than based on birth weight (a full list of nonsignificant variables can be found in Supplementary Table S3).

Expression of CDKN1C was also found to be decreased in the placenta of primiparous women $(\log 10 C D K N 1 C-1.40 \pm 0.33$ in primiparous vs. $-1.14 \pm 0.28$ in multiparous, $p<0.001$ ) and in gestations conceived by assisted reproduction ( $\log 10$ CDKN1C $-1.47 \pm 0.35$ in TRA vs. $-1.22 \pm 0.30$ in spontaneous conceptions, $p<0.001)$. There were no differences by gender of the fetus, presence of labor, complication by pre-eclampsia, maternal smoking habits or between singleton and multiple pregnancies.

Multivariate analysis by direct logistic regression (dependent variable: IUGR yes/no) was performed to rule out the effect of confounding variables with an effect on CDKN1C expression in our sample (primiparity and ART); we also included preeclampsia as a covariate, as it was the only clinical feature with a different prevalence between the IUGR and control groups (prevalence of $22.2 \%$ vs. $3.8 \%$, Chi-square test $p=0.01$ ). Primiparity and ART were finally excluded from the model, as they did not have a statistically significant contribution. The final statistical model (Nagelkerke $R^{2} 0.172, p=0.002$ ) included expression of CDKN1C and presence of preeclampsia. 
A

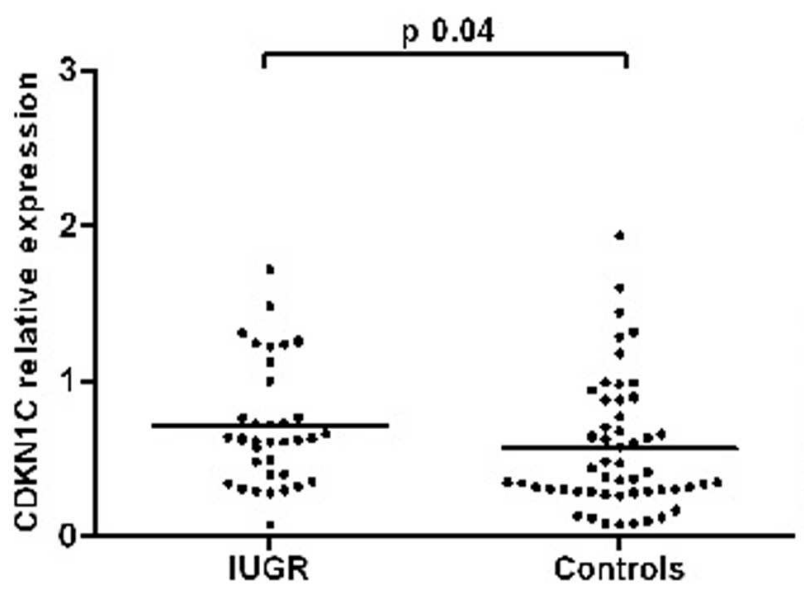

C

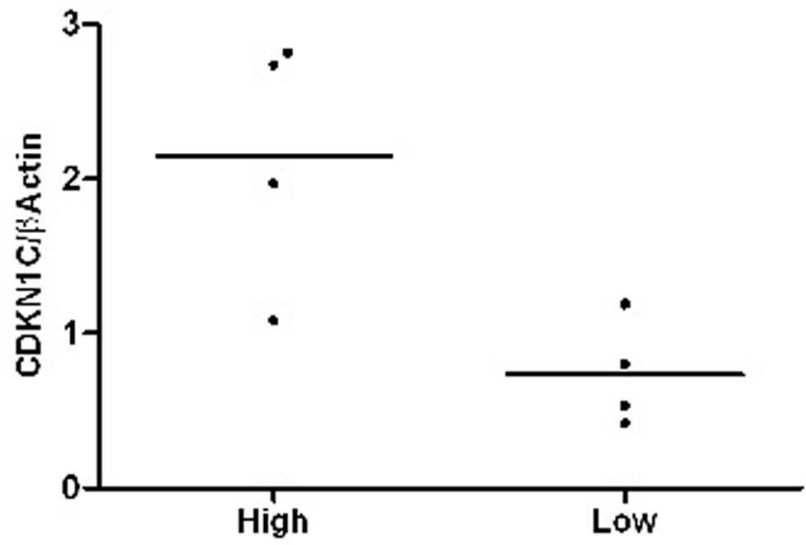

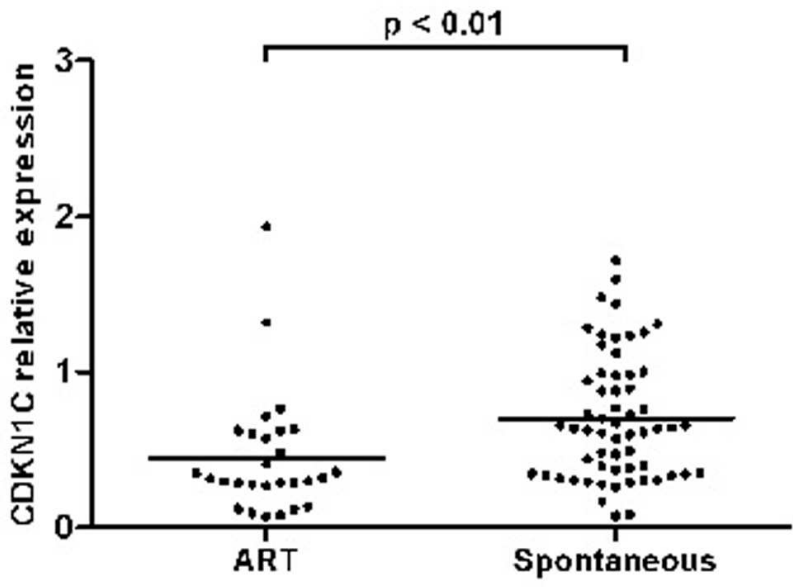

D

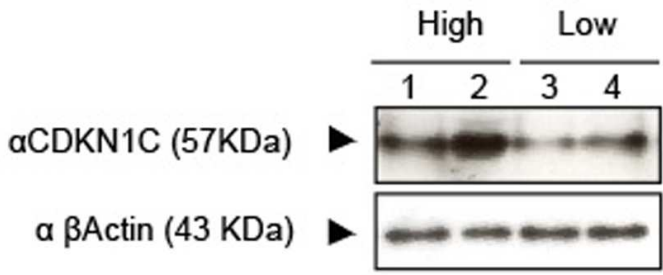

FIGURE 2 | Scatter plots representing RQ (relative quantification) values of CDKN1C transcripts and proteins. (A) A graph showing the transcript abundance of CDKN1C in IUGR and control placenta samples with the line representing the median. (B) The expression profile in ART and spontaneously conceived samples. (C) Quantification of protein expression differences in lowly and highly transcribed placenta samples. (D) An example of a western blot used for protein quantification.

The effect of each of these variables on IUGR was significant [Log10 CDKN1C expression, Exp (B) 4.91, 95\% CI 1.09-22.10, $p=0.038$; preeclampsia, $\operatorname{Exp}$ (B) 5.78 , 95\% CI 1.12-29.73, $p=0.05]$, indicating an independent effect of each of these factors on IUGR.

Western blot analysis revealed that extreme mRNA levels of CDKN1C were also observed at the protein level with higher levels detected in IUGR placentae (Figures 2C,D). However, the difference at the protein level is smaller suggesting there is post-transcriptional regulation of $C D K N 1 C$ in human placenta.

\section{Expression Differences in ART Placenta Biopsies}

Altered levels of expression of imprinted genes have been reported in both mouse and human placentas after the use of assisted reproductive technologies (ART; Katari et al., 2009;
Iglesias-Platas et al., 2014) and placental epigenetic profiles seem particularly vulnerable (Fortier et al., 2008). Levels of expression of CDKN1C were lower in placentas of babies conceived by ART (Figure 2B). In our sample, mothers in the ART group were significantly older $(35.5 \pm 6.3$ vs. $31.9 \pm 5.8$ years, Student's $t$ $p=0.01)$ and taller $(166.7 \pm 6.4$ vs. $162.0 \pm 7.2 \mathrm{~cm}$, Student's t $p=0.01)$, more likely to be primiparous $(89.3 \%$ vs. $52.5 \%$, Chi square $p=0.001)$, to carry a multiple pregnancy ( $78.6 \%$ vs. $16.4 \%$, Chi square $p<0.001$ ) and to be delivered by elective cesarean section, without having undergone labor $(67.9 \%$ vs. $32.8 \%$, Chi square $p=0.02)$. Gestational age at birth was lower in the ART group (32.4 \pm 7.5 vs. $35.4 \pm 4.8$ weeks, Student's $t p=0.04$ ) and baby size was concordantly smaller, but there were no differences regarding anthropometry for gestational age. The groups were similar regarding gender of the newborn and incidence of IUGR and pre-eclampsia. To 
further explore the relationship between ART, expression of CDKN1C and the aforementioned clinical variables, we used hierarchical multiple regression, controlling for the identified confounders. The model including ART, maternal age and height, primiparity, labor and multiple gestation was borderline significant (adjusted $R^{2} 0.112, p=0.05$ ) and ART and multiparity were the only statistically significant contributors to the variance of CDKN1C levels. A linear regression model for the variance of CDKN1C expression including only ART and primiparity had an adjusted $R^{2}$ of $0.174(p<0.001)$, with both clinical values having a significant contribution (ART standardized $\beta=0.249, p=0.01$, primiparity standardized $\beta=0.284$, $p=0.01)$.

\section{Increased Expression in IUGR Despite Maintained Imprinted Expression}

To ensure that CDKN1C maintained monoallelic expression, with transcription solely from the maternal allele, we determined the allelic origin of transcription in all heterozygous individuals. In total 10 samples were heterozygous for the PAPA repeat in exon 2. This represented all groups of gestational age, intrauterine growth and mode of conception. Monoallelic expression was observed in all cases (Figure 3), and origin was confirmed as maternal in three cases with homozygous mothers.

\section{Normal Methylation of CDKN1C in IUGR Placental Samples}

To determine if the differences in expression observed in IUGR and following ART is due to changes in DNA methylation at the CDKN1C promoter we performed pyrosequencing to quantify methylation levels. The bisulfite PCR product incorporated $31 \mathrm{CpG}$ dinucleotides within the amplicon (Figure 4A), with the subsequent pyrosequencing analysis limited to six $\mathrm{CpG}$ dinucleotides due to sequence restrictions for the internal sequence primer and the limited length of the sequence reads. The arithmetic mean of the six $\mathrm{CpG}$ dinucleotides was used as a representative measure of the level of methylation for each placenta sample in our cohort. Pyrosequencing did not detect any differences in methylation between control and IUGR placentae (mean methylation $12.55 \pm 0.53 \%$ in controls vs. $12.13 \pm 0.79 \%$ in IUGR, Student's $t p=0.65$; Figure 4B) or between ART and spontaneously conceived pregnancies (mean methylation
$11.21 \pm 0.60 \%$ in ART vs. $12.86 \pm 0.56 \%$ in spontaneous, Student's $t p=0.09$ ).

Since the maternal expression of $C D K N 1 C$ is regulated in-cis by the KCNQ1OT1:TSS-DMR we also quantified the methylation of this region by pyrosequencing. We observed no deviation from the expected $\sim 50 \%$ methylation in any sample. This suggests that methylation defects at this imprinted DMR are not responsible for the variation in expression levels (Figures 4C,D). This is in agreement with other studies that have shown that changes in imprinted gene abundance in placenta samples are not attributable to methylation defects (Ishida et al., 2012; IglesiasPlatas et al., 2014).

\section{No Evidence for Genetic Variability Influencing CDKN1C Expression}

Since the increased expression of CDKN1C in IUGR babies occurs without loss of imprinting, we hypothesized that underlying genetic variants may influence expression in a similar manner as previously reported for the nearby imprinted gene PHLDA2 (Ishida et al., 2012). We sequenced $\sim 1.2 \mathrm{~kb}$ upstream from the transcription start site, overlapping the promoter $\mathrm{CpG}$ island in two PCR products to identify polymorphisms. The UCSC genome browser (Build GRCh37/hg19) listed five SNPs in this region found in $>1 \%$ of samples, encompassing rs 116430081 to rs431222. However, upon sequence analysis all SNPs were identified in control and IUGR samples with similar frequencies as reported in dbSNP database ${ }^{2}$ (Table 4).

\section{Identifying Long-Range Enhancer Elements for CDKN1C}

Both mouse transgenic studies and data obtained from rare patients with deletions/duplications have suggested that cisacting regulatory elements are required for $C d k n 1 c / C D K N 1 C$ expression, with murine placenta-specific enhancer(s) located $>315 \mathrm{~kb}$ from the gene (John et al., 2001). Recently, a bioinformatics search for conserved non-coding regions harboring the constitutive enhancer histone signature of H3K4me1, H3K27ac, and DNAse1 hypersensitivity sites (Heintzman et al., 2007; Creyghton et al., 2010; Encode Project Consortium, 2012) revealed three likely candidate regions (Cerrato et al., 2014) (Figure 5A). To identify potential CDKN1C

${ }^{2}$ http://www.ncbi.nlm.nih.gov/snp

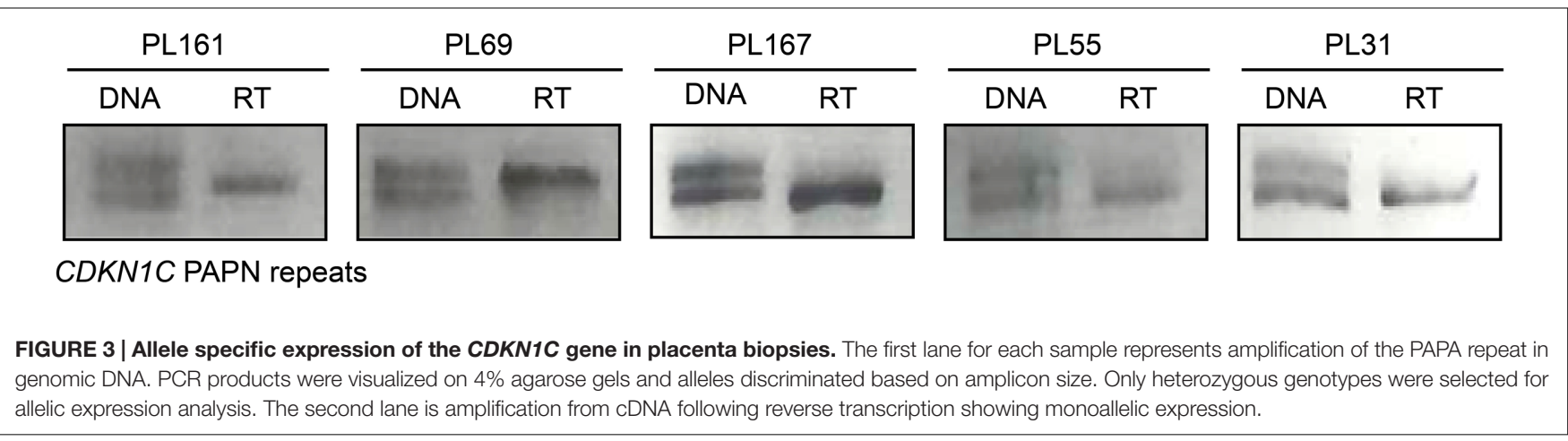




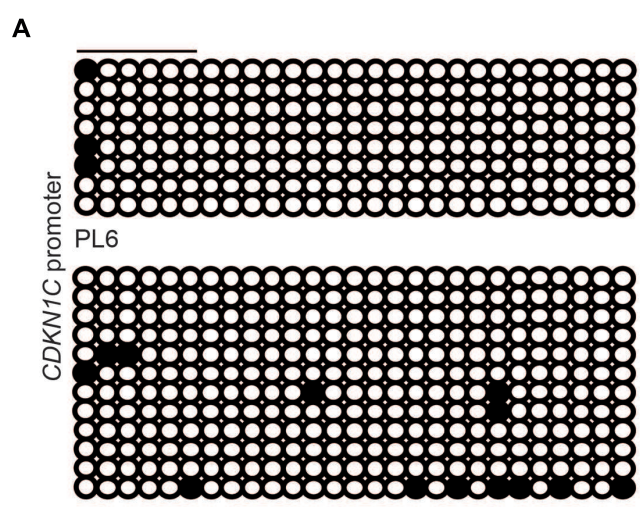

LY3

C

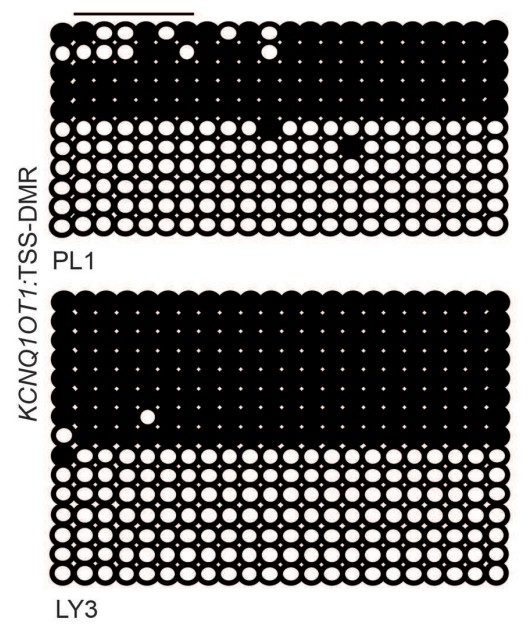

B

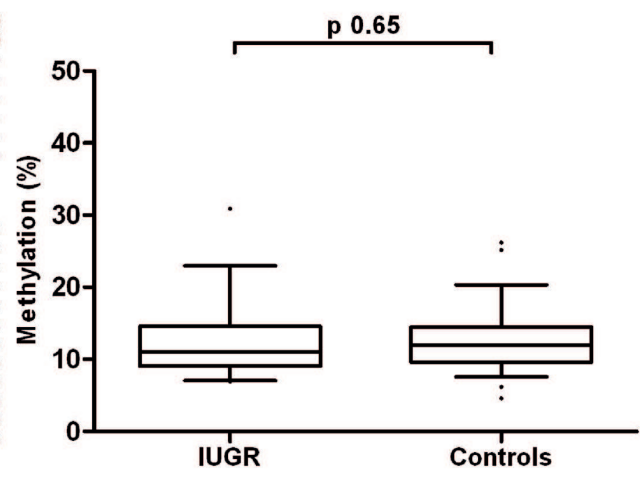

D

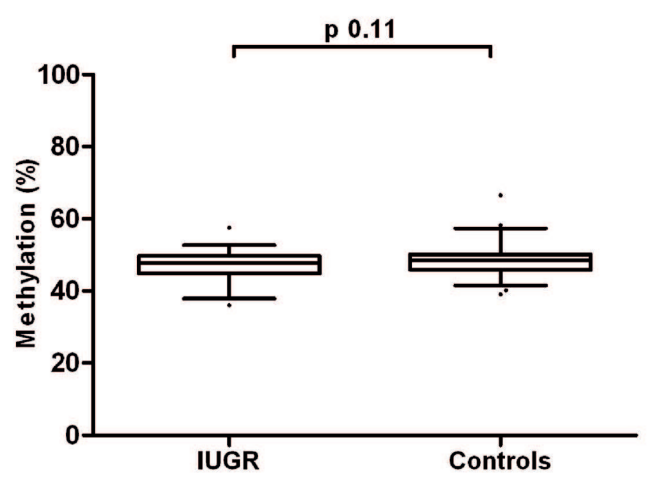

FIGURE 4 | The methylation profiles of the CDKN1C promoter and KCNQ1OT1:TSS-DMR. (A) The left panels show an example of the placental and leukocyte methylation profiles of the $31 \mathrm{CpG}$ dinucleotides analyzed within the CDKN1C promoter CpG island as determined by cloning and direct sequencing. (B) The methylation profiles, representing the average methylation of the six CpGs assayed by pyrosequencing within the CDKN1C promoter. (C) The bisulfite PCR profiling for the $22 \mathrm{CpG}$ dinucleotides analyzed in the KCNQ1OT1:TSS-DMR and (D) the resulting methylation profile as determined by pyrosequencing. Each circle represents a CpG on the strand, and filled circles and open circles indicate methylated and unmethylated sites, respectively. Horizontal lines indicate the CpG sites analyzed by pyrosequencing. PL, placenta; LY, lymphocyte.

enhancers in the human placenta we performed a bioinformatics search for co-localization of H3K4me1 and H3K27ac peaks in datasets generated from fetal placenta tissue available in the GEO data repository (GSM110284; GSM1102795). The ChIP-seq peaks were visualized using the UCSC genome browser ENCODE analysis Hub option. This analysis identified the same three intervals described by Cerrato et al. (2014) using ENCODE ChIP-seq data generated in somatic tissues and cell lines.

\section{Evidence for CTCF Mediated Chromatin Looping between Enhancers and CDKN1C}

Recent studies have revealed that CTCF occupancy mediates intra- and interchromosomal contacts (Holwerda and de Laat, 2013). Several canonical CTCF binding sites within the CDKN1C gene body and proposed enhancer regions were identified using an in silico analysis of ENCODE datasets in multiple tissues (Figure 5A). To confirm in vitro binding we performed ChIP with CTCF antisera on normal lymphoblast cells and placenta (Figure 5B). The efficiency of the ChIP was confirmed by precipitation of the H19/IGF2:IG-DMR and no enrichment of the KCNQ1OT1:TSS-DMR. Subsequent analysis revealed precipitation of CDKN1C and enhancer 3 in both cell types, but not at enhancers 1 and 2, respectively.

Having confirmed CTCF binding at discrete locations within the CDKN1C locus we hypothesize that CTCF dimerization may orchestrate higher order chromatin loops (Rao et al., 2014; de Wit et al., 2015). Next, we interrogated publically available genome-wide ChIA-PET datasets which revealed that the CTCF site within the CDKN1C gene body physically interacts with the CTCF site with enhancer 3 located $\sim 360 \mathrm{~kb}$ away in 
TABLE 4 | SNP reference numbers, genetic variants, and population frequencies listed according to NCBI dbSNP database.

\begin{tabular}{|c|c|c|c|c|c|c|c|}
\hline \multirow[b]{2}{*}{ Enhancer 3} & \multirow{2}{*}{$\begin{array}{c}\text { SNP ID } \\
\text { rs11823023 }\end{array}$} & \multicolumn{2}{|c|}{ Controls } & \multicolumn{2}{|c|}{ IUGR } & \multicolumn{2}{|c|}{ dbSNP 142} \\
\hline & & G: $84 \%$ & A: $16 \%$ & G: $81 \%$ & A: 19\% & G: $85 \%$ & A: $15 \%$ \\
\hline & rs179432 & A: $77 \%$ & G: $23 \%$ & A: $76 \%$ & G: 24\% & A: $70 \%$ & G: 30\% \\
\hline & rs179433 & C: $77 \%$ & T: 23\% & C: $76 \%$ & T: 24\% & C: $70 \%$ & T: 30\% \\
\hline & rs179434 & A: $68 \%$ & C: $32 \%$ & A: $67 \%$ & C: $33 \%$ & A: $57 \%$ & C: $43 \%$ \\
\hline & rs179435 & A: $78 \%$ & G: $22 \%$ & A: $76 \%$ & G: 24\% & A: $67 \%$ & G: $33 \%$ \\
\hline & rs179436 & G: 84\% & A: $16 \%$ & G: $82 \%$ & A: 18\% & G: 83\% & A: $17 \%$ \\
\hline \multirow[t]{4}{*}{ Enhancer 2} & rs2237884 & T: 74\% & C: $26 \%$ & $\mathrm{T:} 73 \%$ & C: $27 \%$ & $\mathrm{T:} 67 \%$ & C: $33 \%$ \\
\hline & rs233434 & G: 91\% & A: $9 \%$ & G: 86\% & A: $14 \%$ & G: 92\% & A: $8 \%$ \\
\hline & rs5789271 & $-: 56 \%$ & G: $44 \%$ & $-: 60 \%$ & G: $40 \%$ & $-: 57 \%$ & G: $43 \%$ \\
\hline & rs12794000 & C: $82 \%$ & T: 18\% & C: $84 \%$ & T: 16\% & C: $84 \%$ & T: 16\% \\
\hline \multirow[t]{3}{*}{ Enhancer 1} & rs202159835 & -: $94 \%$ & $+: 6 \%$ & $-: 88 \%$ & +: $13 \%$ & $-: 99 \%$ & $+: 1 \%$ \\
\hline & rs233451 & G: $78 \%$ & A: $22 \%$ & G: 77\% & A: 23\% & G: $83 \%$ & A: 17\% \\
\hline & rs163184 & C: $58 \%$ & T: $42 \%$ & T: 71\% & T: 29\% & C: $63 \%$ & T: 37\% \\
\hline \multirow[t]{4}{*}{ Promoter } & rs431222 & C: $71 \%$ & T: 29\% & C: $72 \%$ & $\mathrm{~T}: 28 \%$ & C: $79 \%$ & $\mathrm{~T}: 21 \%$ \\
\hline & rs452338 & G: $71 \%$ & T: 29\% & G: $72 \%$ & T: 28\% & G: $79 \%$ & T: 21\% \\
\hline & rs34738237 & $-: 66 \%$ & CA: 34\% & $-: 74 \%$ & CA: $26 \%$ & $-: 74 \%$ & CA: $26 \%$ \\
\hline & rs116430081 & C: $100 \%$ & T: 0\% & C: 99\% & $\mathrm{T}: 1 \%$ & C: $99 \%$ & $\mathrm{~T}: 1 \%$ \\
\hline
\end{tabular}

The frequency of observed genetic variants in our cohort classified as control or IUGR.

both breast (MCF7) and blood (K562) cell lines, indicative of a constitutive chromatin loop (Figure 5A). To confirm this physical interaction we performed chromatin conformation capture experiments (3C) to identify potential chromatin folding. 3C-PCR assays were performed on the placental TCL1 cell line and interaction frequencies were determined between a constant HindIII site located near the CTCF binding site within CDKN1C and other HindIII sites throughout the locus. We identified strong interaction between the CDKN1C constant fragment with the CTCF site in the enhancer region 3 (Figure 5C). Direct sequencing of the PCR product revealed that the appropriate chimeric products result from the $3 \mathrm{C}$ ligations (Figure 5D). Unfortunately no informative SNPs were identified within the vicinity of the HindIII sites associated with these loops that would allow us to determine the parental origin of the resulting chemical products. These results suggest that the CDKN1C expression, at least in placenta, is dependent upon the active enhancer configuration and higher-order chromatin looping.

\section{Determining Genetic and Methylation Variation at Enhancers}

Having identified the putative enhancer regions that may influence the expression of $C D K N 1 C$, we addressed if epigenetic or genetic variation within these regions were associated with IUGR in our samples. We optimized bisulfite pyrosequencing to quantify DNA methylation of multiple CpG dinucleotides within the enhancer regions. The CTCF sites associated with the longrange enhancer 3 are unmethylated in all control samples and we failed to detect any methylation changes with the IUGR profiles being within the control methylation ranges (mean methylation $7.75 \% \pm 0.23 \%$ in controls and $7.83 \% \pm 0.26 \%$ in IUGR, Student's $t p=0.81)$. Similarly, despite tissue-specific differences observed between placenta and leukocytes, we failed to identify methylation changes at enhancer 1 associated with IUGR (mean methylation $13.15 \% \pm 0.46 \%$ in controls and $12.2 \% \pm 0.84 \%$ in IUGR, Student's $t p=0.28)$. However, a small, but statistically significant difference between normal and IUGR placentas was observed at enhancer 2 (mean methylation $64.53 \% \pm 0.92 \%$ in controls and $69.48 \% \pm 0.77 \%$ in IUGR, Student's $t p<0.001$; Figure 6). Furthermore, genotype analysis of polymorphisms within the enhancer regions failed to reveal any haplotypes enriched in the IUGR group (Table 4). This suggests that large variation within the enhancer intervals do not account for the difference in CDKN1C expression observed in IUGR.

\section{DISCUSSION}

Much of the epigenetic research associated with IUGR has focused on imprinted loci since they are critical for early growth and metabolic adaptation; however, most data, including our previous studies (Camprubí et al., 2013; Iglesias-Platas et al., 2014), have revealed that methylation fluctuates very little at these loci. This is presumably due to the fact that most imprinted DMRs are associated with multiple layers of epigenetic regulation (McEwen and Ferguson-Smith, 2010) that tightly maintain gene expression in the face of any environmental perturbation like maternal undernutrition (Radford et al., 2012). In future studies it would be interesting to determine if changes in histone-tail modifications, including lysine methylation, influence expression in samples with normal DNA methylation.

The data presented in this study highlights the role of the imprinted CDKN1C transcript in fetal growth via a placentamediated mechanism. We have shown increased CDKN1C expression in IUGR placentas after adjustment for other variables influencing size at birth. The precise mechanism of action of CDKN1C in the human placenta is unknown, but is likely to involve regulation of the cell cycle. It would be interesting to determine if the aberrant growth associated with higher 
A
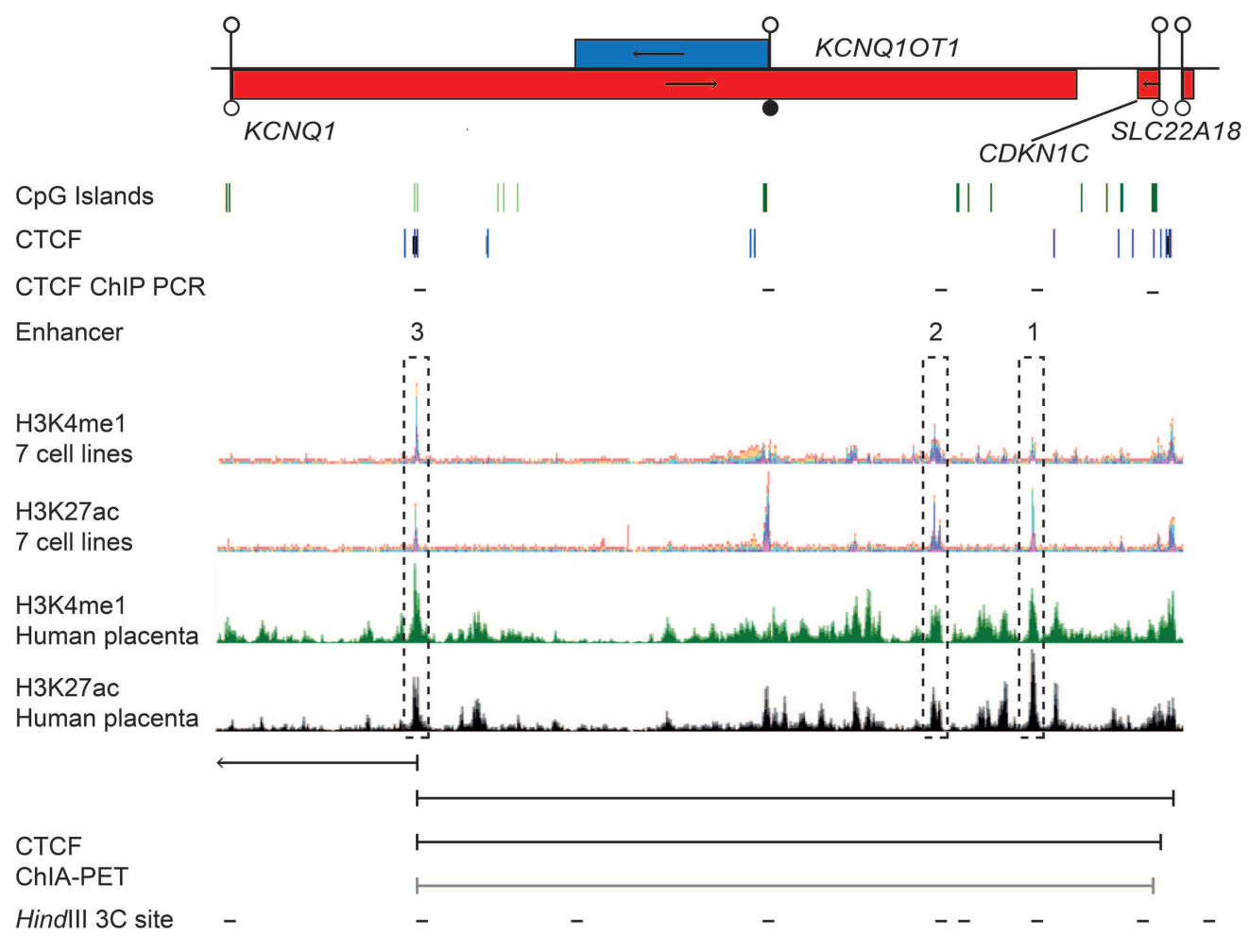

B

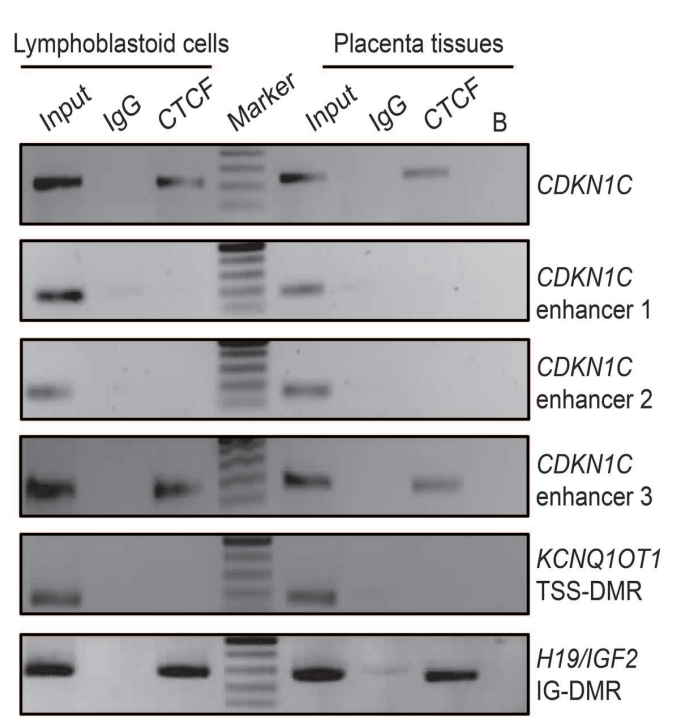

C

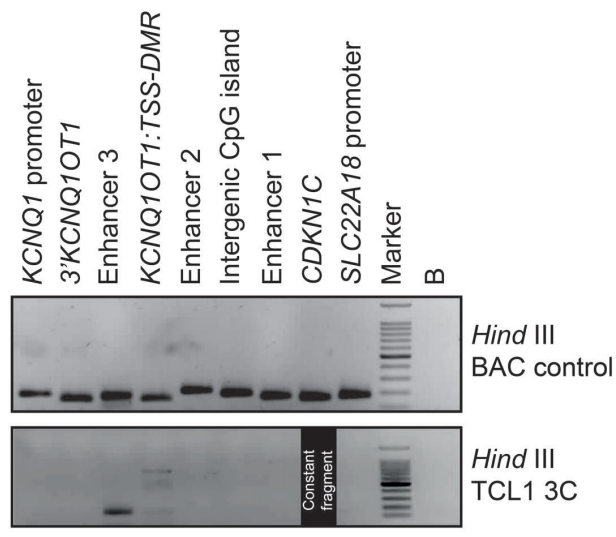

D

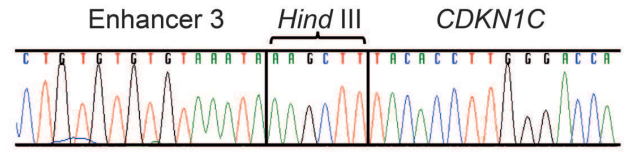

FIGURE 5 | Chromatin conformation capture (3C) interaction across the $440 \mathrm{~kb}$ KCNQ1-CDKN1C region in human placenta. (A) Map of

KCNQ1OT1-CDKN1C domain showing location of three putative enhancer regions in multiple cell types defined by overlapping H3K4me1 and H3K27ac ChIP-seq peaks and the relative position of transcripts, promoter and DMRs. The same intervals also show the canonical histone enhancer signature in first trimester placenta ChIP-seq datasets. ChIA-PET color coding represents signal enrichment based on aligned reads; Black for high frequency interactions, gray for medium intensity interactions. The positions of CTCF sites and Hindlll sites utilized for 3C analysis are shown. (B) CTCF ChIP performed in placenta and lymphoblastoid cells. Input chromatin was used as a positive control (input 5\%). ChIP-recovered DNA, analyzed using PCR and the resulting amplicons visualized using agarose gel electrophoresis. (C) All 3C PCR products were sized and visualized on a 2\% agarose gels. The upper panel depicts the 3C PCR control in Hindlll digested and ligated BAC control DNA. Each target primer combination was analyzed with the reverse primer of the constant region mapping to a Hindlll site within the CDKN1C gene. The lower panel shows the $3 \mathrm{C}$ analysis performed on DNA-derived from cross-linked, digested and ligated chromatin from the placenta cell line TCL1. 3C PCR products of correct size were observed for the enhancer 3 interaction. (D) Sequence analysis reveals the appropriate ligation products following $3 C$ PCR depicting higher-order chromatin contact between the CDKN1C constant fragment and the enhancer 3 region. 
A

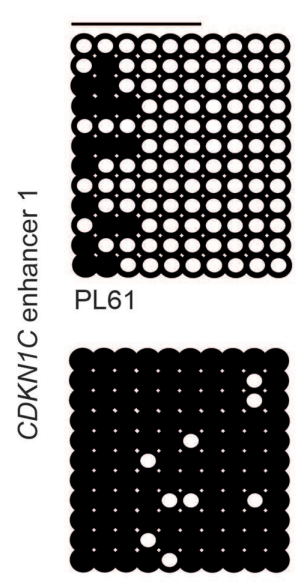

LY9

C

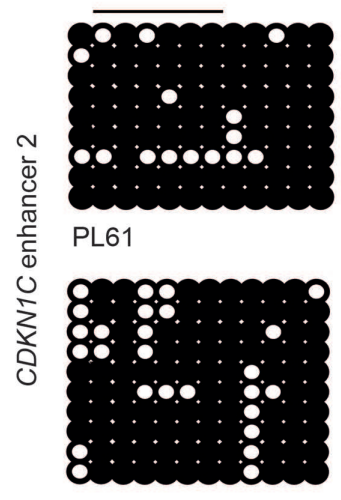

LY14

E

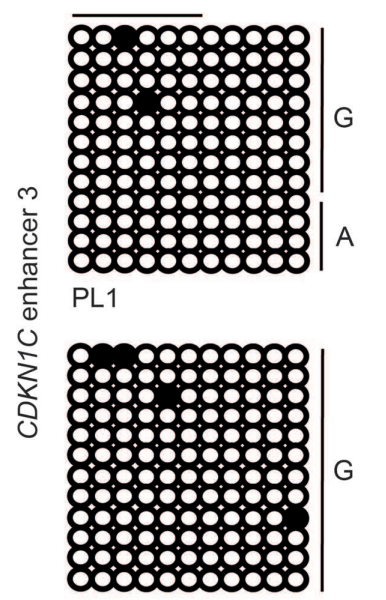

B

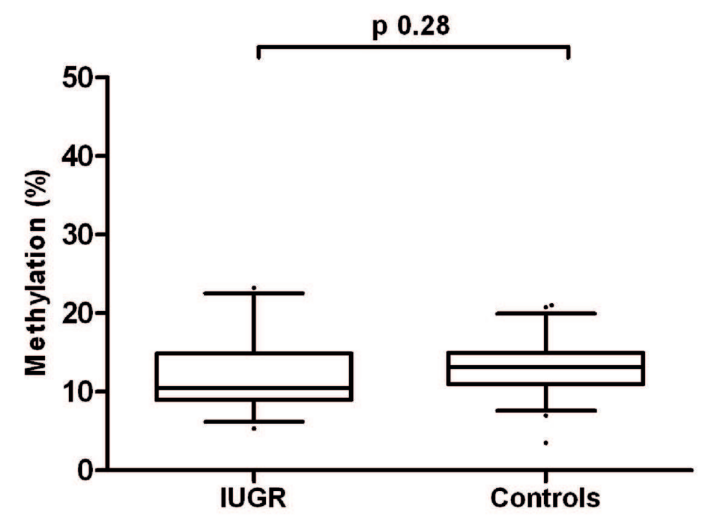

D

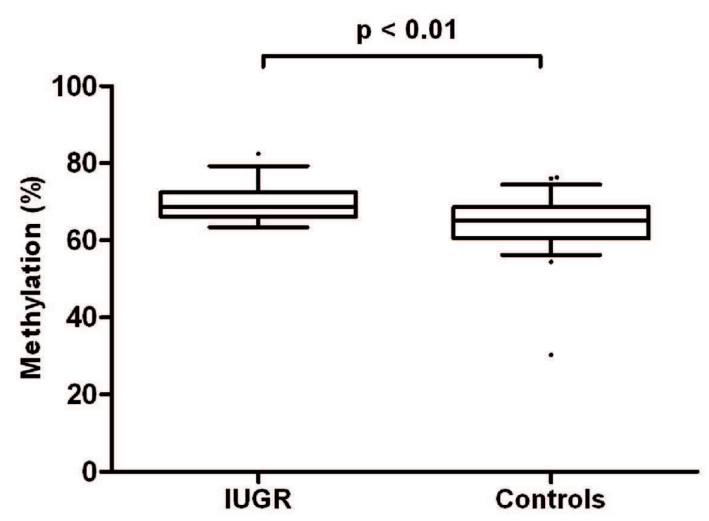

$\mathbf{F}$

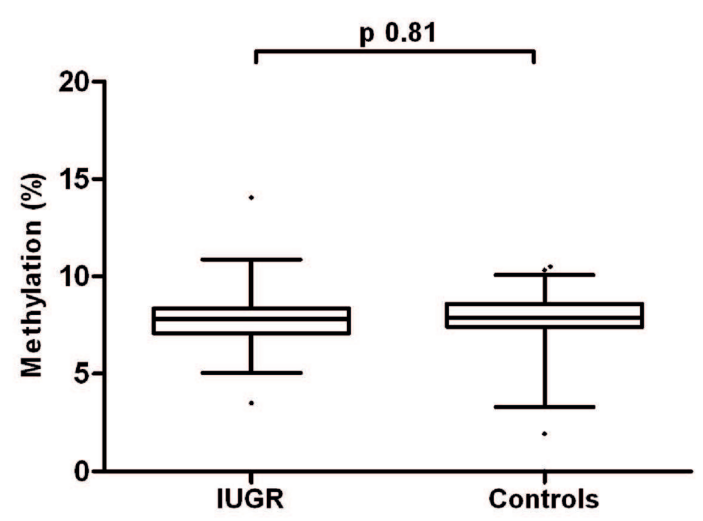

FIGURE 6 | Methylation at the three putative CDKN1C enhancer regions. (A,C,E) The figures represent bisulfite PCR and sequencing for placenta and leukocytes samples where each row corresponds to an individual sequenced DNA clone. Each circle represents a CpG on the strand, and filled circles and open circles indicate methylated and unmethylated sites, respectively. Horizontal lines indicate the CpG sites analyzed by pyrosequencing. (B,D,F) The methylation profiles, representing the average methylation of assayed CpGs as determined by pyrosequencing in IUGR and control control placenta samples. PL, placenta; LY, lymphocyte. 
expression levels of CDKN1C continues following delivery, or if there is catch-up growth indicative of placenta dysfunction. Constitutional growth restriction associated with both IMAGe syndrome and SRS have been reported in rare patients with gain-of-function mutations in the CDKN1C PCNA domain that presumably alters protein clearance by the ubiquitin-proteasome. Whilst, we do not see mutations of this domain in nonsyndromic IUGR (data not shown), we do observe increased protein abundance in IUGR placenta samples. Interestingly the magnitude of increased mRNA expression and protein levels differs greatly, suggesting there is extensive post-transcriptional regulation of CKDN1C. Recently, the microRNA miR-221 has been shown to regulate CDKN1C mRNA levels (Sun et al., 2011) and this specific miRNA has been shown to be plentiful in third trimester/term placentas ( $\mathrm{Gu}$ et al., 2013).

Imprinted gene expression in the placenta can be influenced by many factors including differences in the sampling site, mode of delivery (Janssen et al., 2015), fetal sex (IglesiasPlatas et al., 2014), and gestational age (Demetriou et al., 2014). Regional variation in the expression of PHLDA2 has previously been reported with modest elevation of expression in samples taken at the distal edge of the placenta compared to the ones near the cord insertion site (Janssen et al., 2015) which may partially be attributed to differences in placental architecture and blood supply. To overcome this we routinely obtained biopsies from the same location on the fetal side of the placenta within $2 \mathrm{~cm}$ of the cord insertion. In addition the same authors observed elevated CDKN1C expression in placenta from labored deliveries compared with elective cesarean sections. We do not observe any differences in our larger cohort of samples.

Furthermore difference in expression have can also be modulated by gestational age, with the transcript levels of the PHLDA2 gene showing an association with birth weight (although not IUGR) in term samples (Apostolidou et al., 2007; Ishida et al., 2012) but not in first trimester chorionic villus sampling (Demetriou et al., 2014). Similar gestational age associations have also been observed for additional imprinted genes, including GRB10 in first trimester placenta samples and IGF2 in a series of normal term biopsies (Moore et al., 2015) but it has not been established if differences occur in biopsies from complicated pregnancies. Interestingly different studies have reported conflicting results for CDKN1C influencing fetal size with three reports describing a negative correlation with birth weight (McMinn et al., 2006; Moore et al., 2015; Piyasena et al., 2015). It will be important to verify if changes in imprinted gene expression are a direct cause of pregnancy complications, or alternatively, they may reflect a common adaptive compensatory mechanism in the placenta.

The increased abundance of CDKN1C, we observe in IUGR placentas was not paralleled by changes in methylation at the CDKN1C promoter or KCNQ1OT1:TSS-DMR. Other authors have also found expression levels differences in imprinted genes without obvious methylation changes in the corresponding imprinted DMRs. This presumably reflects transcriptional deregulation by other trans-acting mechanisms, such as transcription factor binding (McMinn et al., 2006; Ishida et al., 2012; Cordeiro et al., 2014; Iglesias-Platas et al., 2014; Piyasena et al., 2015). We have previously shown that the expression levels of PLAGL1 correlated with CDKN1C levels, with PLAGL1 presumably exerting its influence as a zinc finger transcription factor (Iglesias-Platas et al., 2014). However, the precise location of the binding sites are unknown since the long-range enhancer elements have yet to be characterized. Recently a bioinformatics screen for somatic enhancers identified three candidate regions (Cerrato et al., 2014) that are the same as we identified in placenta. Experiments performed by John et al. (2001) using BAC transgenes indicate that, in addition to the DMR within the promoter of Kcnq1ot1, expression of $C d k n 1 c$ requires interaction with a distant tissuespecific enhancer located within the Kcnq1 gene. Using such an approach, the enhancers for expression in the placenta were not identified, suggesting they might be located more than $315 \mathrm{~kb}$ from $C d k n 1 c$. This is consistent with our observation as one of the putative enhancers we identify (region 3) maps $\sim 360 \mathrm{~kb}$ from $C D K N 1 C$ and we show they physically interact in placenta.

We have previously demonstrated that the imprinted domains associated with PLAGL1 (Iglesias-Platas et al., 2014) and PEG13/KCNK9 (Court et al., 2014a) require additional transcription factors or active enhancers to facilitate imprinted transcription from constitutive CTCF-mediated chromatin loops that are stable and independent of transcription. Similarly the data we present here suggest that CTCF orchestrates biallelic higher-order chromatin interactions within the KCNQ1-domain since the binding sites for CTCF, a known methylation-sensitive DNA binding protein responsible for the looping, are all unmethylated. Interestingly, we do not observe CTCF binding within the KCNQ1OT1:TSS-DMR, suggesting that this interval does not act as a methylation-sensitive insulator as has been observed in mice (Du et al., 2003; Shin et al., 2008). However, prominent CTCF binding was observed $5 \mathrm{~kb}$ downstream of the DMR in most tissues analyzed by ENCODE. We hypothesize that the level of CDKN1C transcription is regulated by a combination of the shared enhancers and endogenous promoter sequences, with the latter conferring the allelic specificity due to the accumulation of repressive histone modification on the paternal allele (Monk et al., 2006).

\section{CONCLUSION}

Our results show DNA methylation independent differences of CDKN1C expression in placenta in non-syndromic IUGR and between pregnancies of primiparous versus multiparous mothers and gestations conceived spontaneously or by assisted reproduction. Our results support the idea that distant enhancers physically interact via long-range chromatin looping which in turn regulate $C D K N 1 C$ expression. Deciphering the role of these putative enhancer elements in regulating tissue-specific expression of CDKN1C will be important to understand the molecular etiologies of non-syndromic IUGR, SRS, BWS, and IMAGe syndrome. 


\section{AUTHOR CONTRIBUTIONS}

Conceived and designed the experiments: II-P and DM. Performed the experiments: ML-A, II-P, and DM. Analyzed the data: ML-A, II-P, and DM. Wrote the paper: DM. Discussed and critically edited the manuscript: ML-A, II-P, and DM.

\section{FUNDING}

This work was supported by Spanish Ministerio de Educación y Ciencia (BFU2014-53093 to DM) and by the National R+D+I Plan (PI13/01562 to IIP) of the ISCIII (Subdirección General de Evaluación y Fomento de la Investigación Sanitaria), both cofunded with the European Union Regional Development Fund (FEDER) and Vueling (II-P). During the time this data was generated DM was a Ramón y Cajal research fellow.

\section{ACKNOWLEDGMENTS}

We would like to thank all the families that participated in this study and the clinical staff involved in their care,

\section{REFERENCES}

Andrews, S. C., Wood, M. D., Tunster, S. J., Barton, S. C., Surani, M. A., and John, R. M. (2007). Cdkn1c (p57Kip2) is the major regulator of embryonic growth within its imprinted domain on mouse distal chromosome 7. BMC Dev. Biol. 7:53. doi: 10.1186/1471-213X-7-53

Apostolidou, S., Abu-Amero, S., O’Donoghue, K., Frost, J., Olafsdottir, O., Chavele, K. M., et al. (2007). Elevated placental expression of the imprinted PHLDA2 gene is associated with low birth weight. J. Mol. Med. (Berl.) 85, 379-387. doi: 10.1007/s00109-006-0131-8

Arboleda, V. A., Lee, H., Parnaik, R., Fleming, A., Banerjee, A., Ferraz-de-Souza, B., et al. (2012). Mutations in the PCNA-binding domain of CDKN1C cause IMAGe syndrome. Nat. Genet. 44, 788-792. doi: 10.1038/ng.2275

Begemann, M., Spengler, S., Gogiel, M., Grasshoff, U., Bonin, M., Betz, R. C., et al. (2012). Clinical significance of copy number variations in the $11 \mathrm{p} 15.5$ imprinting control regions: new cases and review of the literature. J. Med. Genet. 49, 547-553. doi: 10.1136/jmedgenet-2012-100967

Brioude, F., Oliver-Petit, I., Blaise, A., Praz, F., Rossignol, S., Le Jule, M., et al. (2013). CDKN1C mutation affecting the PCNA-binding domain as a cause of familial Russell Silver syndrome. J. Med. Genet. 50, 823-830. doi: 10.1136/jmedgenet-2013-101691

Camprubí, C., Iglesias-Platas, I., Martin-Trujillo, A., Salvador-Alarcon, C., Rodriguez, M. A., Barredo, D. R., et al. (2013). Stability of genomic imprinting and gestational-age dynamic methylation in complicated pregnancies conceived following assisted reproductive technologies. Biol. Reprod. 89, 50. doi: 10.1095/biolreprod.113.108456

Carter, A. M., and Enders, A. C. (2004). Comparative aspects of trophoblast development and placentation. Reprod. Biol. Endocrinol. 5, 46. doi: 10.1186/1477-7827-2-46

Caspary, T., Cleary, M. A., Baker, C. C., Guan, X. J., and Tilghman, S. M. (1998). Multiple mechanisms regulate imprinting of the mouse distal chromosome 7 gene cluster. Mol. Cell. Biol. 18, 3466-3474. doi: 10.1128/MCB.18.6.3466

Cerrato, F., De Crescenzo, A., and Riccio, A. (2014). Looking for CDKN1C enhancers. Eur. J. Hum. Genet. 22, 442-443. doi: 10.1038/ejhg.2013.234

Cordeiro, A., Neto, A. P., Carvalho, F., Ramalho, C., and Dória, S. (2014). Relevance of genomic imprinting in intrauterine human growth expression of CDKN1C, H19, IGF2, KCNQ1 and PHLDA2 imprinted genes. J. Assist. Reprod. Genet. 31, 1361-1368. doi: 10.1007/s10815-014-0278-0

Court, F., Camprubi, C., Garcia, C. V., Guillaumet-Adkins, A., Sparago, A., Seruggia, D., et al. (2014a). The PEG13-DMR and brain-specific enhancers especially the perinatal nurses at Hospital Sant Joan de Déu who contributed to the collection of placental samples. We are especially grateful to Marta Sanchez-Delgado for help with pyrosequencing and Franck Court for advice with the $3 \mathrm{C}$ experiment.

\section{SUPPLEMENTARY MATERIAL}

The Supplementary Material for this article can be found online at: http://journal.frontiersin.org/article/10.3389/fgene. 2016.00062

\section{TABLE S1 | Oligonucleotide PCR primers used in this study.}

TABLE S2 | Summary of the experimental results that based our selection for internal control genes in placental tissue. MRPL19, mitochondrial ribosomal transcript; GUS3, glucuronidase 3; HPRT, hypoxanthine guanine phosphoribosyl transferase; NCL, nucleolin; GAPDH, glyceraldehyde-3-phosphate dehydrogenase; MRLPL19 showed the smallest variation between placental samples and the closest amplification characteristics (cycle threshold, $C_{T}$ ) to those of our genes of interest.

TABLE S3 | A summary of non-significant variables that are not associated with changes in CDKN1C expression levels.

dictate imprinted expression within the $8 \mathrm{q} 24$ intellectual disability risk locus. Epigenetics Chromatin 7, 5. doi: 10.1186/1756-8935-7-5

Court, F., Tayama, C., Romanelli, V., Martin-Trujillo, A., Iglesias-Platas, I., Okamura, K., et al. (2014b). Genome-wide parent-of-origin DNA methylation analysis reveals the intricacies of human imprinting and suggests a germline methylation-independent mechanism of establishment. Genome Res. 24, 554569. doi: 10.1101/gr.164913.113

Creyghton, M. P., Cheng, A. W., Welstead, G. G., Kooistra, T., Carey, B. W., Steine, E. J., et al. (2010). Histone H3K27ac separates active from poised enhancers and predicts developmental state. Proc. Natl. Acad. Sci. U.S.A. 107, 21931-21936. doi: 10.1073/pnas.1016071107

de Wit, E., Vos, E. S., Holwerda, S. J., Valdes-Quezada, C., Verstegen, M. J., Teunissen, H., et al. (2015). CTCF binding polarity determines chromatin looping. Mol. Cell 60, 676-684. doi: 10.1016/j.molcel.2015.09.023

Demetriou, C., Abu-Amero, S., Thomas, A. C., Ishida, M., Aggarwal, R., AlOlabi, L., et al. (2014). Paternally expressed, imprinted insulin-like growth factor-2 in chorionic villi correlates significantly with birth weight. PLoS ONE 9:e85454. doi: 10.1371/journal.pone.0085454

Diaz-Meyer, N., Day, C. D., Khatod, K., Maher, E. R., Cooper, W., Reik, W., et al. (2003). Silencing of CDKN1C (p57KIP2) is associated with hypomethylation at KvDMR1 in Beckwith-Wiedemann syndrome. J. Med. Genet. 40, 797-801. doi: 10.1136/jmg.40.11.797

Du, M., Beatty, L. G., Zhou, W., Lew, J., Schoenherr, C., Weksberg, R., et al. (2003). Insulator, and silencer sequences in the imprinted region of human chromosome 11p15. 5. Hum. Mol. Genet. 12, 1927-1939. doi: 10.1093/hmg/ddg194

Eggermann, T., Algar, E., Lapunzina, P., Mackay, D., Maher, E. R., Mannens, M., et al. (2014). Clinical utility gene card for: Beckwith-Wiedemann syndrome. Eur. J. Hum. Genet. 22. doi: 10.1038/ejhg.2013.132

Eggermann, T., Perez de Nanclares, G., Maher, E. R., Temple, I. K., Tümer, Z., Monk, D., et al. (2015). Imprinting disorders: a group of congenital disorders with overlapping patterns of molecular changes affecting imprinted loci. Clin. Epigenetics 7, 123. doi: 10.1186/s13148-015-0143-8

Encode Project Consortium (2012). An integrated encyclopedia of DNA elements in the human genome. Nature 489, 57-74. doi: 10.1038/nature11247

Ferguson-Smith, A. C. (2011). Genomic imprinting: the emergence of an epigenetic paradigm. Nat. Rev. Genet. 12, 565-575. doi: 10.1038/nrg3032

Fortier, A. L., Lopes, F. L., Darricarre're, N., Martel, J., and Trasler, J. M. (2008). Superovulation alters the expression of imprinted genes in the midgestation mouse placenta. Hum. Mol. Genet. 17, 1653-1665. doi: 10.1093/hmg/ddn055 
Gu, Y., Sun, J., Groome, L. J., and Wang, Y. (2013). Differential miRNA expression profiles between the first and third trimester human placentas. Am. J. Physiol. Endocrinol. Metab. 304, E836-E843. doi: 10.1152/ajpendo.00660.2012

Hamajima, N., Johmura, Y., Suzuki, S., Nakanishi, M., and Saitoh, S. (2013). Increased protein stability of CDKN1C causes a gain-of-function phenotype in patients with IMAGe syndrome. PLOS ONE 8:e75137. doi: 10.1371/journal.pone.0075137

Hatada, I., and Mukai, T. (1995). Genomic imprinting of p57KIP2, a cyclindependent kinase inhibitor, in mouse. Nat. Genet. 11, 204-206. doi: 10.1038/ng1095-204

Heintzman, N. D., Stuart, R. K., Hon, G., Fu, Y., Ching, C. W., Hawkins, R. D., et al. (2007). Distinct and predictive chromatin signatures of transcriptional promoters and enhancers in the human genome. Nat. Genet. 39, 311-318. doi: $10.1038 / \mathrm{ng} 1966$

Hiura, H., Obata, Y., Komiyama, J., Shirai, M., and Kono, T. (2006). Oocyte growth-dependent progression of maternal imprinting in mice. Genes Cells 11, 353-361. doi: 10.1111/j.1365-2443.2006.00943.x

Holwerda, S. J., and de Laat, W. (2013). CTCF: the protein, the binding partners, the binding sites and their chromatin loops. Philos. Trans. R. Soc. Lond. B Biol. Sci. 368, 20120369. doi: 10.1098/rstb.2012.0369

Iglesias-Platas, I., Martin-Trujillo, A., Petazzi, P., Guillaumet-Adkins, A., Esteller, M., and Monk, D. (2014). Altered expression of the imprinted transcription factor PLAGL1 deregulates a network of genes in the human IUGR placenta. Hum. Mol. Genet. 23, 6275-6285. doi: 10.1093/hmg/ddu347

Ishida, M., Monk, D., Duncan, A. J., Abu-Amero, S., Chong, J., Ring, S. M., et al. (2012). Maternal inheritance of a promoter variant in the imprinted PHLDA2 gene significantly increases birth weight. Am. J. Hum. Genet. 90, 715-719. doi: 10.1016/j.ajhg.2012.02.021

Janssen, A. B., Tunster, S. J., Savory, N., Holmes, A., Beasley, J., Parveen, S. A., et al. (2015). Placental expression of imprinted genes varies with sampling site and mode of delivery. Placenta 36, 790-795. doi: 10.1016/j.placenta.2015.06.011

John, R. M., Ainscough, J. F., Barton, S. C., and Surani, M. A. (2001). Distant ciselements regulate imprinted expression of the mouse p57( Kip2) (Cdkn1c) gene: implications for the human disorder, Beckwith-Wiedemann syndrome. Hum. Mol. Genet. 10, 1601-1609. doi: 10.1093/hmg/10.15.1601

Katari, S., Turan, N., Bibikova, M., Erinle, O., Chalian, R., Foster, M., et al. (2009). DNA methylation and gene expression differences in children conceived in vitro or in vivo. Hum. Mol. Genet. 18, 3769-3778. doi: 10.1093/hmg/ddp319

Kirchmaier, A. L. (2011). Ub-family modifications at the replication fork: regulating PCNA-interacting components. FEBS Lett. 585, 2920-2928. doi: 10.1016/j.febslet.2011.08.008

Kong, A., Steinthorsdottir, V., Masson, G., Thorleifsson, G., Sulem, P., Besenbacher, S., et al. (2009). Parental origin of sequence variants associated with complex diseases. Nature 462, 868-874. doi: 10.1038/nature08625

Lee, M. H., Reynisdóttir, I., and Massagué, J. (1995). Cloning of p57KIP2, a cyclin-dependent kinase inhibitor with unique domain structure and tissue distribution. Genes Dev. 9, 639-649. doi: 10.1101/gad.9.6.639

Lee, M. P., Hu, R. J., Johnson, L. A., and Feinberg, A. P. (1997). Human KVLQT1 gene shows tissue-specific imprinting and encompasses BeckwithWiedemann syndrome chromosomal rearrangements. Nat. Genet. 15, 181-185. doi: 10.1038/ng0297-181

Lewis, A., Mitsuya, K., Umlauf, D., Smith, P., Dean, W., Walter, J., et al. (2004). Imprinting on distal chromosome 7 in the placenta involves repressive histone methylation independent of DNA methylation. Nat. Genet. 36, 1291-1295. doi: $10.1038 / \mathrm{ng} 1468$

Lim, D. H., and Maher, E. R. (2010). Genomic imprinting syndromes and cancer. Adv. Genet. 70, 145-175. doi: 10.1016/B978-0-12-380866-0.60006-X

Mancini-Dinardo, D., Steele, S. J., Levorse, J. M., Ingram, R. S., and Tilghman, S. M. (2006). Elongation of the Kcnqlotl transcript is required for genomic imprinting of neighboring genes. Genes Dev. 20, 1268-1282. doi: $10.1101 /$ gad.1416906

Matsuoka, S., Edwards, M. C., Bai, C., Parker, S., Zhang, P., Baldini, A., et al. (1995). p57KIP2, a structurally distinct member of the p21CIP1 Cdk inhibitor family, is a candidate tumor suppressor gene. Genes Dev. 9, 650-662. doi: 10.1101/gad.9.6.650

McEwen, K. R., and Ferguson-Smith, A. C. (2010). Distinguishing epigenetic marks of developmental and imprinting regulation. Epigenetics Chromatin 3, 2. doi: $10.1186 / 1756-8935-3-2$
McMinn, J., Wei, M., Schupf, N., Cusmai, J., Johnson, E. B., Smith, A. C., et al. (2006). Unbalanced placental expression of imprinted genes in human intrauterine growth restriction. Placenta 27, 540-549. doi: 10.1016/j.placenta.2005.07.004

Miller, R. J., Sullivan, M. C., Hawes, K., and Marks, A. K. (2009). The effects of perinatal morbidity and environ- mental factors on health status of preterm children at age 12. J. Pediatr. Nurs. 24, 101-114. doi: 10.1016/j.pedn.2008.02.031

Mohammad, F., Pandey, G. K., Mondal, T., Enroth, S., Redrup, L., Gyllensten, U., et al. (2012). Long noncoding RNA-mediated maintenance of DNA methylation and transcriptional gene silencing. Development 139, 2792-2803. doi: 10.1242/dev.079566

Monk, D. (2015). Genomic imprinting in the human placenta. Am. J. Obstet. Gynecol. 213(Suppl. 4), S152-S162. doi: 10.1016/j.ajog.2015.06.032

Monk, D., Arnaud, P., Apostolidou, S., Hills, F. A., Kelsey, G., Stanier, P., et al. (2006). Limited evolutionary conservation of imprinting in the human placenta. Proc. Natl. Acad. Sci. U.S.A. 103, 6623-6628. doi: 10.1073/pnas.0511031103

Moore, G. E., Ishida, M., Demetriou, C., Al-Olabi, L., Leon, L. J., Thomas, A. C., et al. (2015). The role and interaction of imprinted genes in human fetal growth. Philos. Trans. R. Soc. Lond. B Biol. Sci. 370, 20140074. doi: 10.1098/rstb.2014.0074

Okae, H., Hiura, H., Nishida, Y., Funayama, R., Tanaka, S., Chiba, H., et al. (2012). Re-investigation and RNA sequencing-based identification of genes with placenta-specific imprinted expression. Hum. Mol. Genet. 21, 548-558. doi: $10.1093 / \mathrm{hmg} / \mathrm{ddr} 488$

Piyasena, C., Reynolds, R. M., Khulan, B., Seckl, J. R., Menon, G., and Drake, A. J. (2015). Placental 5-methylcytosine and 5-hydroxymethylcytosine patterns associate with size at birth. Epigenetics 10, 692-697. doi: $10.1080 / 15592294.2015 .1062963$

Radford, E. J., Isganaitis, E., Jimenez-Chillaron, J., Schroeder, J., Molla, M., Andrews, S., et al. (2012). An unbiased assessment of the role of imprinted genes in an intergenerational model of developmental programming. PLoS Genet. 8:e1002605. doi: 10.1371/journal.pgen.1002605

Rao, S. S., Huntley, M. H., Durand, N. C., Stamenova, E. K., Bochkov, I. D., Robinson, J. T., et al. (2014). A 3D map of the human genome at kilobase resolution reveals principles of chromatin looping. Cell 159, 1665-1680. doi: 10.1016/j.cell.2014.11.021

Romero, S. T., Geiersbach, K. B., Paxton, C. N., Rose, N. C., Schisterman, E. F., Branch, D. W., et al. (2015). Differentiation of genetic abnormalities in early pregnancy loss. Ultrasound Obstet. Gynecol. 45, 89-94. doi: 10.1002/uog.14713

Sanchez-Delgado, M., Martin-Trujillo, A., Tayama, C., Vidal, E., Esteller, M., Iglesias-Platas, I., et al. (2015). Absence of maternal methylation in biparental hydatidiform moles from women with NLRP7 maternal-effect mutations reveals widespread placenta-specific imprinting. PLoS Genet. 11:e1005644. doi: 10.1371/journal.pgen.1005644

Schmitthen, T. D., and Livak, K. J. (2008). Analysing real-time PCR data by the comparative C(T) method. Nat. Protoc. 3, 1101-1108. doi: 10.1038/nprot.2008.73

Shin, J. Y., Fitzpatrick, G. V., and Higgins, M. J. (2008). Two distinct mechanisms of silencing by the KvDMR1 imprinting control region. EMBO J. 27, 168-178. doi: 10.1038/sj.emboj.7601960

Society for Maternal-Fetal Medicine Publications Committee, Berkley, E., Chauhan, S. P., and Abuhamad, A. (2012). Doppler assessment of the fetus with intrauterine growth restriction. Am. J. Obstet. Gynecol. 206, 300-308. doi: 10.1016/j.ajog.2012.01.022

Sood, R., Zehnder, J. L., Druzin, M. L., and Brown, P. O. (2006). Gene expression patterns in human placenta. Proc. Natl. Acad. Sci. U.S.A. 103, 5478-5483. doi: $10.1073 /$ pnas.0508035103

Sun, K., Wang, W., Zeng, J. J., Wu, C. T., Lei, S. T., and Li, G. X. (2011). MicroRNA221 inhibits CDKN1C/p57 expression in human colorectal carcinoma. Acta Pharmacol. Sin. 32, 375-384. doi: 10.1038/aps.2010.206

Takahashi, K., Nakayama, K., and Nakayama, K. (2000). Mice lacking a CDK inhibitor, p57Kip2, exhibit skeletal abnormalities and growth retardation. J. Biochem. 127, 73-83. doi: 10.1093/oxfordjournals.jbchem.a022586

Thorvaldsen, J. L., Duran, K. L., and Bartolomei, M. S. (1998). Deletion of the H19 differentially methylated domain results in loss of imprinted expression of H19 and Igf2. Genes Dev. 12, 3693-3702. doi: 10.1101/gad.12.23.3693

Tokino, T., Urano, T., Furuhata, T., Matsushima, M., Miyatsu, T., Sasaki, S., et al. (1996). Characterization of the human p57KIP2 gene: alternative splicing, 
insertion/deletion polymorphisms in VNTR sequences in the coding region, and mutational analysis. Hum. Genet. 97, 625-631. doi: 10.1007/BF02281873

Tunster, S. J., Van de Pette, M., and John, R. M. (2011). Fetal overgrowth in the Cdkn1c mouse model of Beckwith-Wiedemann syndrome. Dis. Models Mech. 4, 814-821. doi: $10.1242 / \mathrm{dmm} .007328$

Umlauf, D., Goto, Y., Cao, R., Cerqueira, F., Wagschal, A., Zhang, Y., et al. (2004). Imprinting along the Kcnq1 domain on mouse chromosome 7 involves repressive histone methylation and recruitment of Polycomb group complexes. Nat. Genet. 36, 1296-1300. doi: 10.1038/ng1467

Watanabe, H., Pan, Z. Q., Schreiber-Agus, N., DePinho, R. A., Hurwitz, J., and Xiong, Y. (1998). Suppression of cell transformation by the cyclin-dependent kinase inhibitor p57KIP2 requires binding to proliferating cell nuclear antigen. Proc. Natl. Acad. Sci. U.S.A. 95, 1392-1397. doi: 10.1073/pnas.95.4.1392

Westbury, J., Watkins, M., Ferguson-Smith, A. C., and Smith, J. (2001). Dynamic temporal and spatial regulation of the cdk inhibitor p57(kip2) during embryo morphogenesis. Mech. Dev. 109, 83-89. doi: 10.1016/S0925-4773(01)00512-3
Yatsuki, H., Joh, K., Higashimoto, K., Soejima, H., Arai, Y., Wang, Y., et al. (2002). Domain regulation of imprinting cluster in Kip2/Lit1 subdomain on mouse chromosome 7F4/F5: large-scale DNA methylation analysis reveals that DMRLit1 is a putative imprinting control region. Genome Res. 12, 1860-1870. doi: $10.1101 /$ gr.110702

Conflict of Interest Statement: The authors declare that the research was conducted in the absence of any commercial or financial relationships that could be construed as a potential conflict of interest.

Copyright $\odot 2016$ López-Abad, Iglesias-Platas and Monk. This is an open-access article distributed under the terms of the Creative Commons Attribution License (CC BY). The use, distribution or reproduction in other forums is permitted, provided the original author(s) or licensor are credited and that the original publication in this journal is cited, in accordance with accepted academic practice. No use, distribution or reproduction is permitted which does not comply with these terms. 